\title{
Aproximaciones a la capacidad de acogida de las playas como recurso turístico en tiempos de la COVID-19:
}

\section{el caso de la costa atlántica andaluza}

Approaches to the beaches carrying capacity in times of COVID-19: the case of the Andalusian Atlantic coast

\section{Antonio Prieto Campos}

pcampos@us.es

\section{Pilar Díaz Cuevas}

pilard@us.es

Departamento de Geografía Física y Análisis Geográfico Regional

Universidad de Sevilla (España)

\section{Resumen}

El anuncio de la apertura de la temporada turística de verano en España en plena pandemia producida por el coronavirus SARS CoV-2 trajo consigo diversas incertidumbres vinculadas a garantizar el ejercicio de la actividad en condiciones de seguridad sanitaria. En este trabajo se realiza una primera aproximación a la capacidad de las playas atlánticas andaluzas para absorber la demanda recreativa y turística. Para ello se calcula la superficie de playa útil, utilizando la última ortofotografía aérea disponible (2016) y las funcionalidades analíticas de los Sistemas de Información Geográfica. Se construyen tres escenarios de ocupación en función de la superficie de playa útil por usuario y del establecimiento de uno o dos turnos de visita. 
Los resultados muestran como el escenario 1, menos restrictivo, podría acoger en un solo turno a la totalidad de los usuarios potenciales. El escenario 2 sólo podría acoger a todos los usuarios mediante el establecimiento de dos turnos y en el escenario 3, ni con el establecimiento de dos turnos se podría acoger a los residentes. Si bien los resultados deben ser completados con análisis a escalas más detalladas, suponen una necesaria primera aproximación que puede resultar de utilidad para la toma de decisiones.

Palabras clave: playa útil; turismo; fachada atlántica; COVID-19; SIG.

\begin{abstract}
The announcement of the start of the summer tourist season in Spain, in the middle of the SARS CoV-2 pandemic, although it is an encouraging new, brought with it a number of uncertainties linked to guaranteeing the exercise of the activity in conditions of health safety. In this paper, an initial approximation to Andalusian Atlantic beaches carrying capacity to absorb the recreational and tourist demand has been carried out. For this purpose, the useful beach area is calculated, using the latest available aerial orthophotography (2016) and the analytical functionalities of the Geographical Information Systems. Three occupation scenarios are built according to the useful beach area per user and the establishment of one or two visiting shifts. The results show how scenario 1 could accommodate all of the potential users in a single shift. Scenario 2 could only accommodate all users by establishing a double shift and in scenario 3, neither the establishment of a double shift could accommodate residents. Although the results must be completed with analysis at more fine scales, they are a necessary first approximation that can be useful for decision making.
\end{abstract}

Key words: suitable beaches; tourism; Atlantic coast; COVID-19; GIS.

\title{
1 Introducción
}

El turismo constituye uno de los sectores que mayor crecimiento ha experimentado en los últimos 50 años. Así mientras que, tras la Segunda Guerra Mundial, 25 millones de personas en todo el mundo viajaron fuera de sus países de origen con fines turísticos, en 2018, el sector registró un total de 1401 millones de llegadas internacionales y 1451 billones de dólares (OMT, 2019). Este crecimiento ha sido, por lo general, continuado a lo largo del tiempo, si bien se ha visto afectado por determinados eventos como crisis económicas, epidemias, terrorismo o conflictos bélicos (Nieto et al., 2016). 
El 11 de marzo de 2020 la Organización Mundial de la Salud (OMS) declaró el brote de la enfermedad COVID-19 pandemia global. Con la aparición de este, la industria turística ha sufrido un gran impacto inicial. A falta de datos que determinen los impactos a largo plazo, hoy día el sector se enfrenta a lo que podría definirse como el mayor reto de su existencia. La Organización Mundial del Turismo (en adelante OMT) estima unos impactos globales sobre el sector que superan las crisis producidas con anterioridad debido a los eventos previamente mencionados, al menos en cuanto a su repercusión en el número de llegadas internacionales e ingresos por turismo internacional (OMT, 2020). Ello se debe principalmente a que la capacidad de recuperación del sector se ve intensamente afectada por la imposición de medidas que restringen la movilidad, elemento imprescindible para la actividad turística (Hall et al., 2020).

De este modo, se estima una bajada del número de llegadas internacionales respecto al año 2019 que oscilaría entre el 20 y el 30 \% para el año 2020, y una pérdida de entre 300 y 450 billones de dólares en ingresos por turismo internacional. Ello supone, en el peor de los casos, casi un tercio de los ingresos generados a nivel mundial (OMT, 2020). No obstante, se piensa que los principales impactos tendrán lugar a lo largo de 2021 (Ekstein, 2020).

En España, el turismo constituye en la actualidad uno de los sectores clave de la economía (Vizcaíno, 2015), siendo el país del mundo donde el sector aportó más al PIB en 2018 (en torno al $11 \%$ ) de manera directa o indirecta (OECD, 2018). Si bien en los últimos años el turismo cultural constituye uno de los que ha alcanzado mayor relevancia (Cánoves et al., 2016), el turismo de sol y playa sigue siendo determinante y es el litoral el espacio donde se ubica el 70 $\%$ de las plazas hoteleras y se realizan el $75 \%$ de las pernoctaciones totales (Instituto Geográfico Nacional, 2018).

En el caso andaluz, según datos del último Balance Turístico de Andalucía, los ingresos por turismo se han estimado en 20,6 miles de millones de euros, representando el 12,8 \% del PIB de la región en 2017. Ese año, casi 30 millones de turistas visitaron la región, de los que más de la mitad, casi 17 millones, visitaron el litoral (Consejería de Turismo y Deporte, 2017a).

Efectivamente, las playas constituyen uno de los recursos más importantes en cualquier destino turístico, donde la ocupación intensiva ha supuesto, en algunos casos, la aparición de algunos procesos degradantes (erosión, alteración del perfil de la playa, contaminación, etc.) que ponen en peligro su viabilidad como recurso natural y turístico y que han incrementado su vulnerabilidad frente al cambio climático. 
En un intento por limitar la presión que se genera sobre los destinos o recursos turísticos y evitar su saturación, la medición de la capacidad de carga turística de los espacios litorales se ha convertido en un indicador de gran importancia.

Desde el punto de vista turístico, la capacidad de carga se define como "el número máximo de personas que pueden visitar un lugar al mismo tiempo sin causar la destrucción del medio físico, económico, socio-cultural y una disminución inaceptable en la calidad de la satisfacción de los visitantes" (OMT, 1981). Este concepto, en su sentido amplio, se refiere a la capacidad de un sistema para soportar una actividad o característica en un nivel determinado y se vincula a la necesidad de equilibrar el desarrollo y las actividades a un nivel tanto ecológicamente como socialmente sostenible (Lim, 1998). Aunque único, este concepto incorpora varios tipos de capacidad de carga, que pueden resumirse en: capacidad de carga física, psicológica o perceptual, ecológica, social y económica (Hunter, 1995; Butler, 1996; Echamendi, 2001; Shridar et al., 2016).

Frente a este escenario de limitar el aforo para un uso sostenible de las playas, que evite la saturación de estos elementos y, por tanto, que garantice su pervivencia como recurso natural y turístico, la pandemia COVID-19 pone de manifiesto la necesidad de limitar el aforo para garantizar la seguridad sanitaria. Obtener el dato de aforo es fundamental para una correcta gestión de las playas que aumente la sensación de seguridad del visitante y permita mantener los negocios locales que viven de esta actividad en los destinos turísticos. Destaca en línea con esta idea el trabajo de Botero et al. (2020), que aborda un análisis general de la crisis de la COVID19 y recoge las impresiones de expertos en gestión y certificación de playas de América Latina y Europa. Además, el trabajo establece una serie de recomendaciones de acción muy generales, aplicables a cualquier playa turística, pero que ayuda a la toma de decisiones de los gestores durante la pandemia y posterior a ella.

Entre las 16 recomendaciones destaca por su importancia para este trabajo, aquella dirigida a reducir la densidad de usuarios en función de la sectorización y zonificación (recomendación 11). Según esta, hasta que la epidemia no se supere, el regreso a las playas debería centrarse en la mayor distribución posible de los visitantes en las mismas. Para ello entre otras medidas se establece, una densidad de usuarios recomendada siempre superior a $10 \mathrm{~m}^{2}$ por usuario.

En línea con estos autores, Yepes (2020), como respuesta a la situación de pandemia actual, definió un método de medición de aforo basado en la aplicación de una serie de coeficientes correctores que deberían ajustarse según las condiciones específicas de cada playa. Son 
múltiples las variables propuestas por este autor para la determinación del aforo de una playa: distancia de seguridad sanitaria, ocupación estática y dinámica segura, porcentaje de usuarios susceptible de contagio, tipo y porcentaje de ocupación de la playa, tamaño de las "unidades de convivencia", zonificación de la playa por usos, temperatura de la arena, velocidad y dirección de la brisa, carrera de marea, curva horaria de uso de la playa, curva diaria de uso de la playa, separación entre accesos a la playa, separación de pasillos intermedios en zona de reposo, rango de tiempo mínimo y máximo de disfrute de la playa, velocidad de movimiento de los bañistas en la playa y gestión de colas, entre otras. Sin duda, constituye el método más completo de cálculo de aforo de la playa en las circunstancias de pandemia actuales, no obstante, la consecución de estas variables puede resultar complicada y requeriría de un análisis en profundidad de cada playa específica.

En el caso de España, la Orden SND/440/2020, de 23 de mayo, en su artículo 46.1 establecía que "el tránsito y permanencia en las playas, así como la práctica de actividades deportivas, profesionales o de recreo, se realizarán en los términos previstos en el apartado 2 del artículo 7 de esta orden, siempre que en este último caso se puedan desarrollar individualmente y sin contacto físico, y que se mantenga una distancia mínima de dos metros entre los participantes"

En el caso de Andalucía, en puertas de la temporada turística de sol y playa, el sector se encontraba paralizado ante la epidemia del coronavirus. El gobierno regional reforzó su plan de acción turística para 2020 en función de diversos escenarios, que transitaban por recuperar, primeramente, el mercado regional y nacional (ya que el $67 \%$ de los turistas que llegaron a Andalucía en 2019 fueron nacionales) (Consejería de Turismo y Deporte, 2017b) y, posteriormente, el mercado internacional.

Con carácter general, el Consejo de Gobierno andaluz aprobó el Decreto-ley 14/2020, de 26 de mayo, por el que se establecían con carácter extraordinario y urgente medidas para la reactivación del sector de la hostelería, restauración, ocio y esparcimiento. También se contemplaban medidas de apoyo a las Entidades Locales necesarias para contribuir a la apertura de playas seguras ante la situación de alerta sanitaria generada por el coronavirus (COVID-19) (BOJA, 2020a). En él, se establecían medidas de aforo para los establecimientos de hostelería y restauración para consumo en el local, locales de discotecas y bares de ocio nocturno. En el caso de los hoteles, se limita el aforo máximo del 50\% en las zonas comunes. 
Para el caso de las playas, el Decreto-ley refiere a las medidas de seguridad expuestas en el Decreto-ley 12/2020, de 11 de mayo (BOJA, 2020b), con especial incidencia en los aspectos relacionados con el aforo, acceso, señalización, medidas de distanciamiento y cuantas otras que contribuyan a mejorar la seguridad de las personas en playas, conforme a las recomendaciones e instrucciones de los órganos competentes. No obstante, este Decreto-ley no establecía una ocupación límite de las playas. Correspondía en última instancia a los Ayuntamientos la elaboración de planes de contingencia individualizados frente a la COVID-19, en los que se establecerían las medidas necesarias que permitiesen garantizar el uso seguro de las playas.

Junto a estas medidas, el Gobierno andaluz contrató aproximadamente 3000 auxiliares para el control de sus playas, que realizaron labores de información del control de acceso y aforo de las playas. Asimismo, garantizaron el cumplimiento de las medidas contenidas en el plan de contingencia de cada ayuntamiento e indicaron a los ciudadanos los avisos y comunicados que se realicen por los órganos competentes en materia de emergencias y protección civil (Durán, 2020, June 5).

A pesar de ello, son varios los episodios de desalojo de playas producidos en la región andaluza a lo largo del verano, aunque también es destacable el éxito del distanciamiento social producido en las playas de Chipiona (Cádiz), donde una vista aérea de una playa de Regla, mostraba que todas las sombrillas y toallas estaban colocadas respetando la distancia de seguridad recomendada por las autoridades sanitarias (Díaz, 2020, July 28).

Realizar aproximaciones a la capacidad de acogida de las playas andaluzas para absorber la demanda resulta fundamental, y más ante la alerta sanitaria actual, donde el cumplimiento de las garantías de salud necesarias se convierte, por tanto, en un elemento de gran importancia. Dicha capacidad de acogida pasa por obtener el dato del aforo, fundamental para que los Ayuntamientos puedan tomar decisiones respecto al control de accesos, planificación o evacuación de una playa en caso de necesidad (Yepes, 2020). El dato de aforo depende, en gran parte, de la superficie disponible de playa.

En base a esta idea, este trabajo presenta dos objetivos cuya consecución ayudará a la toma de decisiones por parte de las administraciones implicadas:

1. Realizar aproximaciones a la superficie de playa y capacidad de acogida existente en los municipios costeros de la fachada atlántica andaluza.

2. Establecer valoraciones entre la capacidad de acogida de las playas y la demanda recreativa y turística potencial en condiciones de calidad y garantía necesarias. 


\section{2 Área de estudio}

Con aproximadamente $917 \mathrm{~km}$ de línea de costa, constituyendo el 17,5\% del litoral español (Ojeda et al., 2013), Andalucía cuenta con un total de $620 \mathrm{~km}$ de playas expuestas que suponen casi el 70 \% del frente costero de la región (Figura 1).

Desde el punto de vista turístico, Andalucía se puede considerar como un destino de sol y playa (Consejería de Turismo y Deporte, 2017a). Un total de 60 municipios andaluces cuentan con línea de costa, que representan un 9,1\% del territorio andaluz. Estos concentran el $36 \%$ de la población andaluza y más del 65 \% de las plazas turísticas regladas de la región en 2019 (SIMA, 2020). Todo ello convierte a este sensible territorio en uno de los espacios más presionados de la región.

Dada la gran importancia que el turismo de sol y playa posee para el turismo regional, los últimos años la región andaluza ha potenciado una serie de medidas para su desestacionalización. Destaca el Plan de Choque contra la Estacionalidad del Turismo Andaluz (Consejería de Turismo y Comercio, 2015), que incorporaba un abanico de medidas y actuaciones, tales como la creación de una Red de Municipios contra la Estacionalidad o mostrar Andalucía como destino diverso, plural y en funcionamiento todo el año, entre otras. Estas medidas continuaron en el II Plan de Choque contra la Estacionalidad Turística del Litoral Andaluz 2016-2018, el cual incorporaba un total de 57 actuaciones (Consejería de Turismo y Deportes, 2017c).

A pesar de todas estas medidas, la estacionalidad de este segmento turístico sigue siendo muy elevada, de manera que, en 2017, el 46,6\% de todas las visitas al litoral andaluz se concentraron en el tercer trimestre del año, coincidiendo con el periodo vacacional por excelencia (Consejería de Turismo y Deporte, 2017b). Todo ello intensifica aún más la presión sobre este espacio.

Entre las actividades más frecuentes realizadas por el turista litoral en el destino andaluz se encuentra, en primer lugar, el uso y disfrute de la playa, llevado a cabo por el 78,6 \% del total, siendo el segundo recurso turístico más valorado después del clima (Consejería de Turismo y Deporte, 2017b). 
Figura 1. Área de estudio

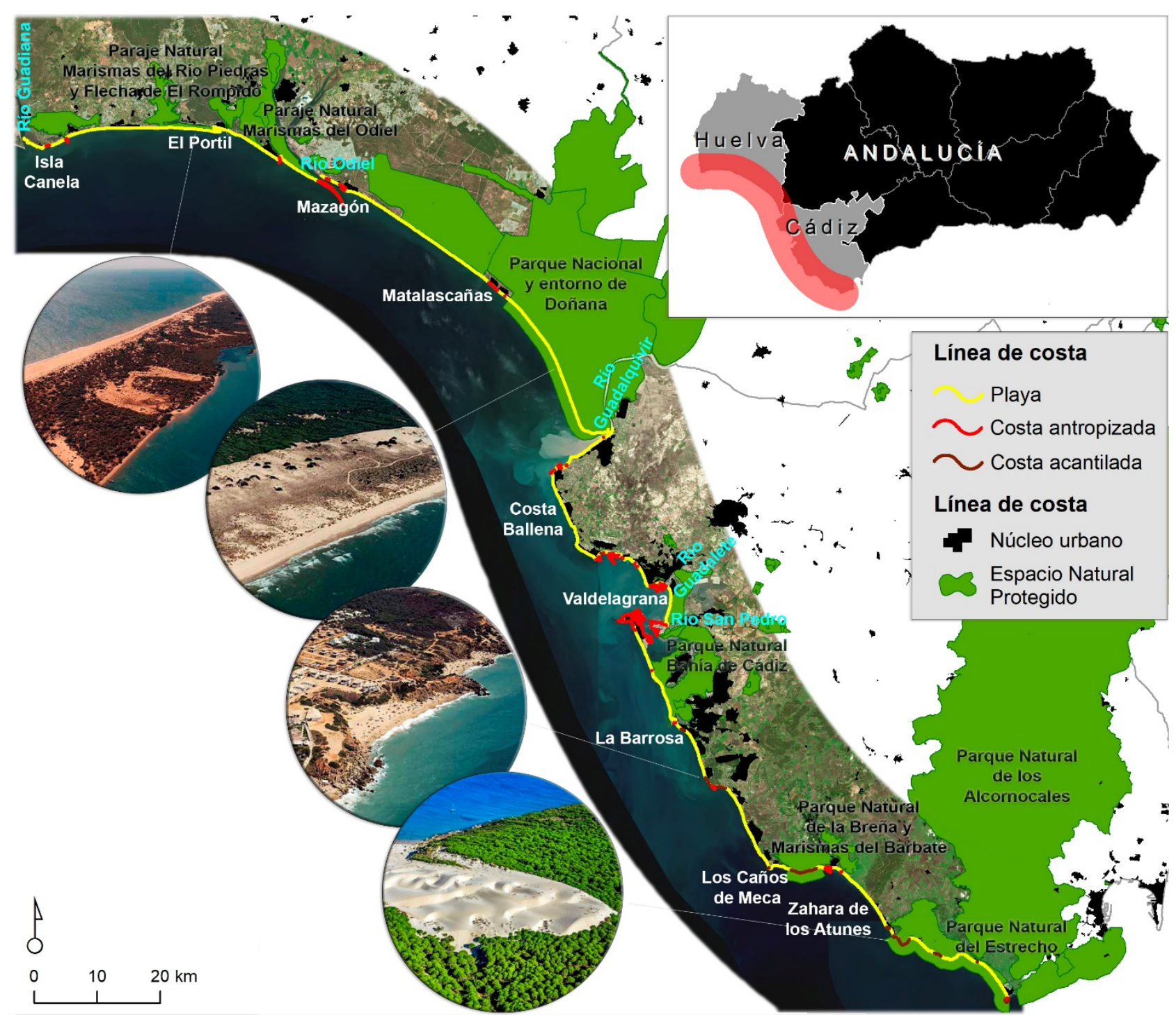

Fuente: elaboración propia a partir de fotografías procedentes de la Guía de Playas del Ministerio para la Transición Ecológica y el Reto Demográfico (MITECO, 2020)

Las playas andaluzas se integran en dos fachadas con características hidrodinámicas y geomorfológicas diferentes, la fachada atlántica y la mediterránea. Ello confiere a este espacio una gran diversidad territorial y paisajística, siendo posible identificar en éste diferentes modelos de implantación y desarrollo turístico (Santos, 2008; García, 2000).

Teniendo en cuenta el límite entre ambas fachadas establecido en este trabajo (punta de Tarifa), las playas son más frecuentes en la fachada atlántica $(250 \mathrm{~km})$, donde representan el $80 \%$ del frente costero. Este porcentaje se reduce al 63 \% en su homóloga mediterránea (Prieto-Campos, 
2017), debido a la presencia de una costa más rocosa y entrecortada, con una gran densidad de infraestructuras y un alto grado de antropización y urbanización (Villar, 2011).

Con un total de 924166 habitantes (a fecha de 1 de enero de 2019) distribuidos en 21 municipios, la fachada atlántica dispone de $324 \mathrm{~km}$ de línea de costa, de los cuáles $255 \mathrm{~km}$ se corresponden con playas expuestas. Los municipios de esta fachada cuentan con un total de 76 playas de las 326 existentes en Andalucía.

En contraposición con su homóloga mediterránea, esta fachada se caracteriza por la presencia generalizada de un relieve suave, lo que ha propiciado la generación de amplias playas de arena de granulometría fina y escasa pendiente tanto en la playa seca como submarina, alimentadas por cordones dunares de notable entidad que protegen espacios de marisma (Ojeda, 1988). El relieve plano va dando paso, conforme descendemos en latitud, a playas con presencia de acantilados de altura notable, muchas de ellas en forma de calas con independencia sedimentaria. La granulometría paulatinamente pasa a ser más gruesa y el perfil de mayor pendiente, con presencia ascendente de formaciones flyschoides conforme nos acercamos al Complejo de Gibraltar (Martín-Serrano, 1985).

Esta fachada presenta un nivel de antropización relativamente bajo debido a, fundamentalmente, dos factores condicionantes. En primer lugar, el desarrollo tardío del turismo y de viviendas de segunda residencia en el sector atlántico (sobre todo el subsector onubense), debido a su situación periférica, a excepción de áreas urbanas propias de núcleos costeros tradicionales y capitales provinciales (aglomeraciones urbanas de Huelva y Bahía de Cádiz), así como de núcleos turísticos puntuales consolidados de baja densidad (Isla Canela, El Portil, Matalascañas, Costa Ballena, La Barrosa, Caños de Meca o Zahara de los Atunes, entre otros). Pese a dicho desarrollo tardío, en los últimos años ha visto incrementado su crecimiento (García, 2000; Santos, 2008). En segundo lugar, la presencia de espacios naturales protegidos, que evitan la ocupación de la franja costera o, al menos, la regulan sustancialmente (Gómez, 2010). En este aspecto, la vertiente atlántica presenta $130 \mathrm{~km}$ de costa protegidos (43\% del total) correspondientes al Parque Nacional y entorno de Doñana, Parques Naturales de Bahía de Cádiz, Estrecho, La Breña y Marismas del Barbate y Parajes Naturales de las Marismas de Isla Cristina, rio Piedras y Odiel.

Desde el punto de vista turístico, en la vertiente atlántica es posible diferenciar entre la costa de la luz onubense y la costa de la luz gaditana. Un total de 3711018 viajeros visitaron la costa de la luz onubense y gaditana, registrando un total de 13368864 pernoctaciones (Tabla 1). 
Los datos ponen de manifiesto un predominio de visitantes nacionales y una elevada estacionalidad.

Atendiendo al número de plazas turísticas, la fachada atlántica aglutina 175770 plazas turísticas, de las cuales 108045 corresponden a la oferta tradicional (SIMA, 2020) y 67725 a viviendas con fines turísticos.

Tabla 1. Viajeros y pernoctaciones en la costa onubense y gaditana en 2019

\begin{tabular}{|c|c|c|c|c|}
\hline Tipo viajero & $\begin{array}{c}\text { Viajeros } \\
\text { totales }\end{array}$ & $\begin{array}{c}\text { Viajeros verano } \\
\text { (junio-sept.) }\end{array}$ & Pernoctaciones & $\begin{array}{c}\text { Pernoctaciones } \\
\text { verano (junio-sept.) }\end{array}$ \\
\hline Nacional & 2573698 & 1586946 & 8654731 & 5937268 \\
\hline Internacional & 1137320 & 539341 & 4714136 & 2451145 \\
\hline Total & 3711018 & 2126287 & 13368867 & 8388413 \\
\hline
\end{tabular}

Fuente: elaboración propia a partir de Encuesta de Ocupación Hotelera, Encuesta de ocupación en campings y Encuesta de ocupación en apartamentos turísticos (INE, 2020)

\section{Metodología y fuentes}

La delimitación del aforo óptimo de las playas para garantizar la seguridad sanitaria en tiempos de la pandemia COVID-19 depende de la capacidad de acogida de las mismas y requiere del establecimiento de ciertos perímetros de metros de distancia de manera que, una vez se complete el aforo, se restringiría el acceso a la playa.

La capacidad de acogida de las playas, depende principalmente de tres variables: la superficie de playa útil, la determinación de una superficie óptima por usuario y la restricción temporal de actividad. En este trabajo, a tenor de la incertidumbre existente sobre la determinación de esta superficie óptima por usuario, se ha renunciado a realizar una única aproximación para medir el número máximo de personas que pueden visitar la playa (A). Su cálculo queda expresado en la Eq. 1.

$$
\text { Eq. 1. } A=\frac{s}{s v} x t
$$

Donde $A=$ capacidad de acogida de las playas en condiciones de seguridad necesarias; $S=$ superficie de playa disponible; $S v=$ superficie requerida por usuario y $t=$ cantidad de turnos diarios. 
En este sentido, el cálculo del número máximo de usuarios que pueden visitar al mismo tiempo la playa se basa en la consecución de tres fases claramente diferenciadas: i) el cálculo de la superficie de playa útil; ii) la determinación de playa útil por usuario y iii) la definición de uno o varios turnos según el tiempo de visita.

A continuación, se tratará en profundidad cada una de las fases mencionadas.

\subsection{Cálculo de la superficie de playa requerida por usuario}

La capacidad de carga turística de las playas es entendida como el número máximo de usuarios que pueden ocupar la playa (Pereira da Silva, 2002). Se relaciona directamente con la capacidad de carga física de las playas y, en esencia, con la delimitación de una superficie óptima de playa requerida por usuario ( $\mathrm{m}^{2} /$ usuario) que garantice el disfrute de la playa.

La superficie óptima de playa requerida por usuario varía notablemente según los autores. De este modo, mientras que Sridhar et al. (2016) determinan este límite en los $5 \mathrm{~m}^{2} /$ usuario, otros autores establecen que valores menores de $4,5 \mathrm{~m}^{2} /$ usuario (Yepes, 1999) y de $10 \mathrm{~m}^{2} /$ usuario (Betancourt y Herrera-Moreno, 2005) empiezan a ser cuestionables desde el punto de vista de la saturación turística. Por su parte, Roig (2002) establece una superficie de $15 \mathrm{~m}^{2} /$ usuario para los destinos turísticos estacionales, si se persigue evitar la saturación y un uso y disfrute sostenible de la playa.

No obstante, este número debe tener en cuenta no sólo la arena, sino también la zona de baño. Aquí es donde se contemplan los principales inconvenientes para la medición, dado que algunas estimaciones suponen que el límite de ocupación de la zona de baño por usuario es de 2,3 $\mathrm{m}^{2}$ para una profundidad menor de 1,6 m (PDH, 2002; DPH, 2005; NYS, 2005). La delimitación de la profundidad de la playa a escala detallada, por tanto, puede resultar complicada y exige de levantamientos topobatimétricos, que suelen resultar difíciles y costosos de obtener. Igualmente, la variabilidad del perfil en la playa submarina es alta y, por otro lado, calcular el número máximo de personas pueden nadar de forma segura depende de la percepción humana y de la tolerancia al riesgo (Silva and Ferreira, 2013).

Otros aspectos deben evaluarse cuidadosamente en el cálculo de la capacidad de carga física. Así, por ejemplo, la distancia a un centro urbano cercano, la accesibilidad a la playa, la disponibilidad de aparcamientos, las condiciones de acceso a la playa, la existencia de salvavidas, restaurantes, instalaciones de ocio (Hecock, 1983) y, en particular, el comportamiento y las características de las personas (sexo, edad, socio-económico) (Pereira da Silva, 2002), son aspectos a tener en cuenta en la medición de la capacidad de carga física de las playas. 
Para el establecimiento del área óptima requerida por usuario $\left(\mathrm{m}^{2} /\right.$ usuario), para disfrutar de la playa en condiciones que garanticen la seguridad sanitaria, deben cumplirse como mínimo las medidas de distanciamiento social. De este modo, la Organización Mundial de la Salud, plantea conservar al menos un metro de distanciamiento social (OMS, 2019), pero mantiene la necesidad de evitar visitar lugares con aglomeraciones de gente. Igualmente, desde el Gobierno de España, la distancia de seguridad que se prevé mantener es de dos metros, medida que se ve complementada con la limitación del aforo.

Son varias las referencias encontradas para la determinación de distancia para el uso y disfrute seguro de las playas, las cuales, además, establecen medidas de superficie muy dispares. Los ya mencionados Botero et al. (2020) determinaron una superficie recomendada superior a $10 \mathrm{~m}^{2}$ por usuario, hasta que se supere totalmente la pandemia.

Por su parte, en España, la ya mencionada Orden SND/440/2020 de 23 de mayo, en su artículo 46.1 establecía una distancia mínima de dos metros. Esta medida constituye el espacio estándar internacional delimitado por la Organización Mundial del Turismo (OMT, 2005) para realizar actividades recreativas en espacios públicos en condiciones normales ( $4 \mathrm{~m}^{2} /$ usuario).

Existen también para el caso de España otras aproximaciones llevadas a cabo en por algunos municipios en cuanto a la determinación de la superficie de playa necesaria por usuario en tiempos de la COVID-19 (Tabla 1). Así, por ejemplo, en el caso de Sanxenxo (Pontevedra), el Ayuntamiento planificó dividir las playas en cuadrículas de $9 \mathrm{~m}^{2}$ para dos personas (Peláez, 2020, April 30) (que en función del tamaño del grupo se ampliarán mediante la retirada de cuerdas para dar cabida a más personas). Otros ayuntamientos, como el de Vélez Málaga, pusieron en marcha la delimitación de cuadrículas de' 6,25 $\mathrm{m}^{2}$ en los $22 \mathrm{~km}$ de playas de su litoral (Pedrido \& López, 2020, May 6).

Dada la ya comentada variabilidad en la determinación de superficie de playa por usuario, y con idea de no limitar o condicionar los resultados a una única medida, se han establecido en este trabajo tres posibles escenarios basados en la asignación de tres medidas diferentes de superficie de playa útil por usuario. De este modo, en el escenario 1 (el más permisivo) se ha utilizado la superficie estimada por el Gobierno central, es decir, $4 \mathrm{~m}^{2} /$ usuario. En el escenario 2 se ha utilizado la superficie establecida por Botero et al. (2020) de $10 \mathrm{~m}^{2} /$ usuario. Dado que estas dos superficies son inferiores a las establecidas por otros autores para evitar la saturación turística y garantizar un uso sostenible de la playa, un tercer escenario ha sido calculado, 
asignando una superficie de $15 \mathrm{~m}^{2}$ por cada usuario, en línea con Roig (2002). De este modo se obtendrán tres aproximaciones diferentes, en función del grado de restricción aplicado.

Junto con estas medidas, para garantizar el acceso a las parcelas en cada uno de los escenarios, se han reservado pasillos de dos metros de anchura, los cuales se han contemplado como área computable en cada parcela, añadiendo un metro de ancho adicional a cada una de ellas de cara a facilitar el cálculo de la capacidad de acogida de cada playa (Figura 2).

De esta manera, se han determinado cuadrículas de superficie por cada dos usuarios para cada escenario. En el escenario 1 (parcelas de 2,82 × 3,82 m), la superficie total de cada parcela tiene un total de 10,8 $\mathrm{m}^{2}$ (Figura 2), para el escenario $2(4,47 \times 5,47 \mathrm{~m})$ tiene $24,5 \mathrm{~m}^{2}$ y para el escenario $3(5,47 \times 6,47), 35,5 \mathrm{~m}^{2}$.

Figura 2. Ejemplo de cálculo de parcelación respetando un pasillo de dos metros para el escenario 1

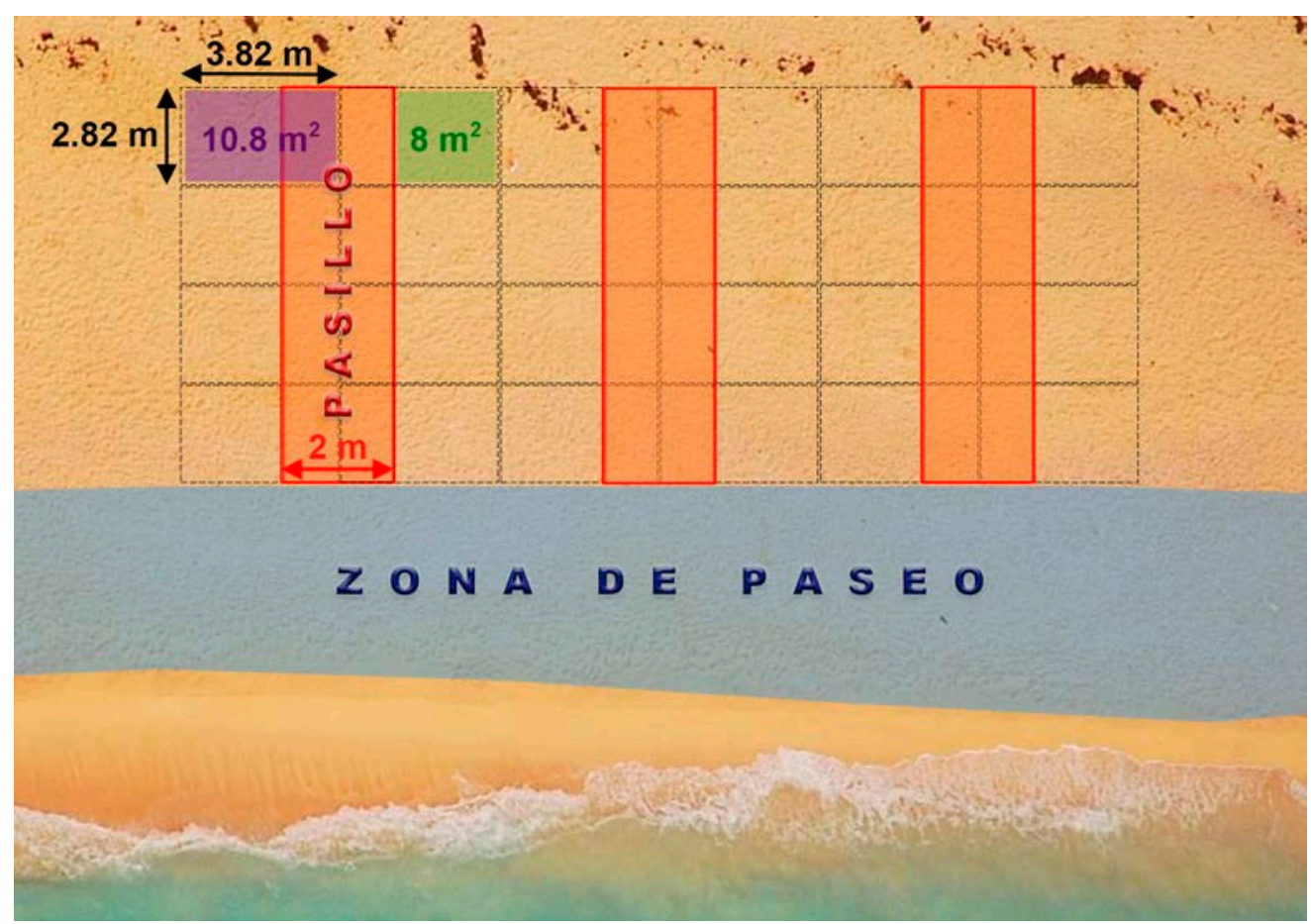

Fuente: elaboración propia

\subsection{Cálculo de la superficie de playa útil}

Una vez definidas las superficies de playa requeridas por usuario en cada escenario, el siguiente paso consiste en calcular la superficie de playa útil existente en la fachada atlántica.

El Coastal Engineering Research Center, CERC (1984), define la playa como: "la acumulación de sedimento no consolidado (arena, grava o canto rodado) que se sitúa entre la línea de 
máximo alcance del oleaje en temporal y pleamar viva y una profundidad que corresponde a la zona donde deja de producirse un movimiento activo de sedimentos debido a la acción del oleaje". Esta definición de playa, además de por su amplia difusión y uso, se asume porque engloba factores tan importantes como la identificación de los límites de la playa, todavía hoy en proceso de acuerdo y aceptación. Ello se debe a que su carácter dinámico, influenciado principalmente por la acción del oleaje y, en menor medida, por la acción combinada del viento y otros agentes meteorológicos y antrópicos, impide una demarcación estable de los límites de la misma (Prieto-Campos, 2017).

Como recurso turístico, la playa disponible se identifica con la playa seca o backshore, delimitada por dos indicadores de línea de costa: la última marca húmeda de la pleamar y el contacto con la duna o con vegetación, pie de acantilado o infraestructura (Figura 3). La acotación de los límites superior e inferior del backshore, derivados de estos indicadores utilizados, permite definir el perímetro y, por consiguiente, la superficie de la misma (DíazCuevas et al., 2020a), obteniéndose datos cuantitativos de la "playa seca", también denominada "playa útil" en estudios turísticos de capacidad de carga física de las mismas.

En este trabajo, las delimitaciones han sido obtenidas mediante fotointerpretación directa y posterior digitalización en software propietario ArcGis 10. El sistema de referencia usado ha sido el European Terrestrial Reference System (ETRS) 1989, proyectado en UTM para los husos 29 y 30 norte, siguiendo el Real Decreto 1071/2007. En este proceso se han definido los mismos criterios desarrollados para la línea de costa multipropósito de Andalucía (Fernandez-Nuñez et al., 2015). De este modo, la fotointerpretación y digitalización han sido realizadas a escala detallada 1:2500 por un solo fotointérprete, caracterizando cada segmento de línea de costa con información temática asociada (Prieto-Campos et al., 2018).

La ortofotografía base sobre la que se ha realizado el levantamiento de datos proviene del vuelo fotogramétrico del PNOA 2015-2016 (última ortofotografía disponible) en RGB e infrarrojo cercano (IRC), con una resolución espacial de 0,25 metros para la zona de estudio. El vuelo fotogramétrico fue realizado en verano, coincidente con el perfil de calma o estabilidad de la playa y con la temporada de la marcada estacionalidad turística. 


\section{Figura 3. Indicadores de línea de costa}
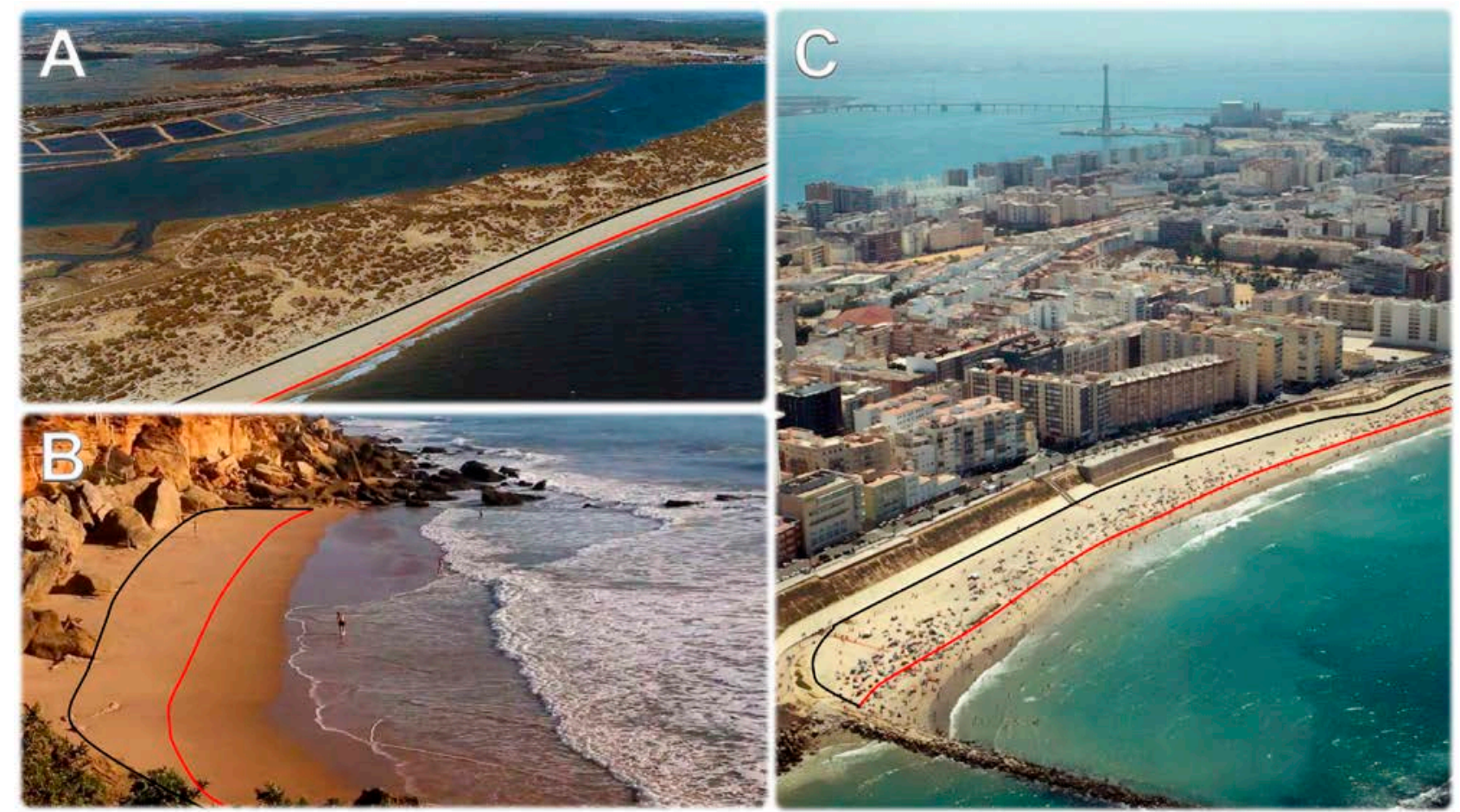

Leyenda: En rojo, límite de pleamar; en negro, contacto con duna o vegetación (A), pie de acantilado (B) o infraestructura (C).

Fuente: elaboración propia a partir de fotografías de la Guía de Playas del MITECO (A), www.conilplaya.com (B) y http://www.leda.es (C).

Una vez fotointerpretados y digitalizados los indicadores de línea de costa, se ha obtenido el polígono que representa la superficie total de playa. Este cálculo ha tenido que ser reajustado en base a los siguientes criterios:

- Se ha reservado una franja de espacio de 4 metros desde la línea de pleamar para paseos, ya que suele ser el área donde se desarrollan la mayoría de actividades recreativas, además de ser la zona de entrada y salida al mar. Este criterio ha sido aplicado homogéneamente a lo largo de todas las playas del área de estudio, teniendo prioridad sobre las parcelas de los usuarios. De esta manera, ante la presencia de un sector costero angosto, prevalece el derecho de paseo al de reposo.

- Se han excluido aquellas áreas de servidumbre militar restringidas al acceso y al baño, por motivos estratégicos de seguridad. En el área de estudio se han excluido los tramos costeros correspondientes a la Base Naval de Rota (Rota y El Puerto de Santa María) y Torregorda (Cádiz y San Fernando). 
- Se han descartado aquellas playas encajadas de pequeña extensión, cuyo relieve abrupto y ausencia de acceso hacen imposible su uso. Son el caso de pequeñas calas localizadas en la base de los acantilados de Barbate y Tarifa. Por su escaso peso, tanto en longitud como en superficie, no han sido tenidas en cuenta en los resultados globales.

Una vez sustraídos al área total de playa los tramos de playas excluidos por las causas arriba descritas, el área resultante es la superficie de playa útil.

Dada la existencia en el área de estudio de zonas alejadas de cualquier acceso a la playa, se ha limitado a $2 \mathrm{~km}$ la distancia máxima asumible para un usuario entre el último acceso (a pie si es playa urbana o motorizado -aparcamiento- si no es urbana) y la parcela de playa disponible.

No obstante, el aislamiento derivado de la dificultad de acceso a la playa puede convertirse, en este escenario, en un garante de menor densidad de visitantes y mejores condiciones sanitarias y, por lo tanto, en un factor de atracción. Por otra parte, la menor oferta de espacios de playa produce un trasvase de los potenciales usuarios hacia playas habitualmente menos frecuentadas.

En el área de estudio se han encontrado casos de limitación de distancia en las siguientes playas: Playa de Castilla, entre los núcleos costeros de Mazagón (Palos de la Frontera) y Matalascañas (Almonte); playa de Doñana, dentro del Parque Nacional de Doñana, entre este último núcleo y la desembocadura del Guadalquivir; y playa de Levante, dentro del Parque Metropolitano Marisma de los Toruños y Pinar de la Algaida, entre el núcleo costero de Valdelagrana (El Puerto de Santa María) y la desembocadura del río San Pedro.

Constituyen playas naturales, por lo general bien conservadas, donde un incremento de aforo podría ejercer una mayor presión en los ecosistemas. Por ello, si bien estas playas serán contabilizadas el análisis, se establecerán en todos los escenarios una medida de ocupación por usuario dirigidas a evitar la saturación turística y garantizar un uso sostenible de la playa (15 $\mathrm{m}^{2}$ /usuario según Roig, 2002).

\subsection{Tiempo de visita}

En relación al tiempo, Fernández y Bértola (2014) establecen que el visitante permanece en la playa un promedio máximo de 6 horas por día. En el caso de Andalucía, el gobierno regional planteó la posibilidad de limitar la actividad a 4 horas en la playa (por la mañana, mediodía o por la tarde), para no derivar en aglomeraciones (León, 2020, May 20). Dos posibilidades han sido aquí valoradas: que el visitante pase todo el día la playa (un turno) o que pase la mitad del día (dos turnos). 


\section{Resultados}

\subsection{Superficie y capacidad de acogida en las playas de los municipios costeros de la}

\section{fachada atlántica andaluza}

La Tabla 2 muestra las superficies totales de playa, excluidas y de playa útil existentes en la fachada atlántica andaluza. La superficie de playa útil para toda la fachada alcanza un total 8,5 $\mathrm{km}^{2}$, siendo las playas de la provincia de Cádiz las que mayor superficie útil aportan, en torno a $4,5 \mathrm{~km}^{2}$, sólo 0,5 km² más que la provincia de Huelva. En general, la superficie total de playa de ambas provincias no difiere en exceso $\left(4,3 \mathrm{~km}^{2}\right.$ y $5 \mathrm{~km}^{2}$ para Huelva y Cádiz, respectivamente), no obstante, el $11 \%$ de la superficie de playas de Cádiz ha sido excluida, frente al $8 \%$ de las playas de Huelva.

Tabla 2. Superficie de playa total, excluida y útil $\left(\mathrm{m}^{2} ; \%\right)$ por provincias

\begin{tabular}{|c|c|c|c|c|c|}
\hline Provincia & $\begin{array}{c}\text { Superficie } \\
\text { total }\left(\mathrm{m}^{2}\right)\end{array}$ & $\begin{array}{c}\text { Superficie } \\
\text { excluida }\left(\mathrm{m}^{2}\right)\end{array}$ & $\begin{array}{c}\text { Superficie } \\
\text { excluida } \\
(\%)\end{array}$ & $\begin{array}{c}\text { Superficie útil } \\
\left(\mathrm{m}^{2}\right)\end{array}$ & $\begin{array}{c}\text { Superficie } \\
\text { útil }(\%)\end{array}$ \\
\hline Huelva & 4294593 & 348058 & 8,1 & 3946535 & 91,9 \\
\hline Cádiz & 5081839 & 570724 & 11,2 & 4511115 & 88,8 \\
\hline Total & 9379432 & 918782 & 9,8 & 8457650 & 90,2 \\
\hline
\end{tabular}

Fuente: elaboración propia

Atendiendo a las causas de exclusión (Figura 4 y Anexo I), la mayor superficie excluida se debe a la delimitación de la zona de paseo y entrada y salida al agua $(4 \mathrm{~m})$ en ambas fachadas, si bien en las playas de la provincia de Cádiz, es resaltable la presencia de zonas de servidumbre militar como principal causa exclusión. Para el caso de Huelva, lo es la presencia de construcciones sobre la playa.

Una vez obtenida la superficie de playa útil por provincias, se ha calculado la capacidad de acogida en cada uno de los escenarios (Figura 5). En el caso del escenario 1, computado para superficies de 10,8 $\mathrm{m}^{2}$ por cada dos usuarios, la superficie de playa útil de la fachada atlántica posibilita el alojamiento de 1326317 usuarios al día en un turno y de 2652634 en caso de dos turnos. Para el segundo escenario, calculado para superficies de $24,5 \mathrm{~m}^{2}$ por cada dos usuarios, la capacidad de acogida disminuye a 643312 usuarios para un turno al día y 1286624 para dos turnos. Por último, en el caso del escenario 3, que determina superficies de 
$35,5 \mathrm{~m}^{2}$ por cada dos usuarios, la capacidad de acogida disminuye notablemente, alcanzando los 476473 usuarios o los 952946 en uno o dos turnos, respectivamente.

A lo largo de los apartados siguientes, se realizará un análisis en profundidad de los resultados obtenidos.

Figura 4. Superficie de playa excluida según causa por provincias $\left(\mathrm{m}^{2}\right)$

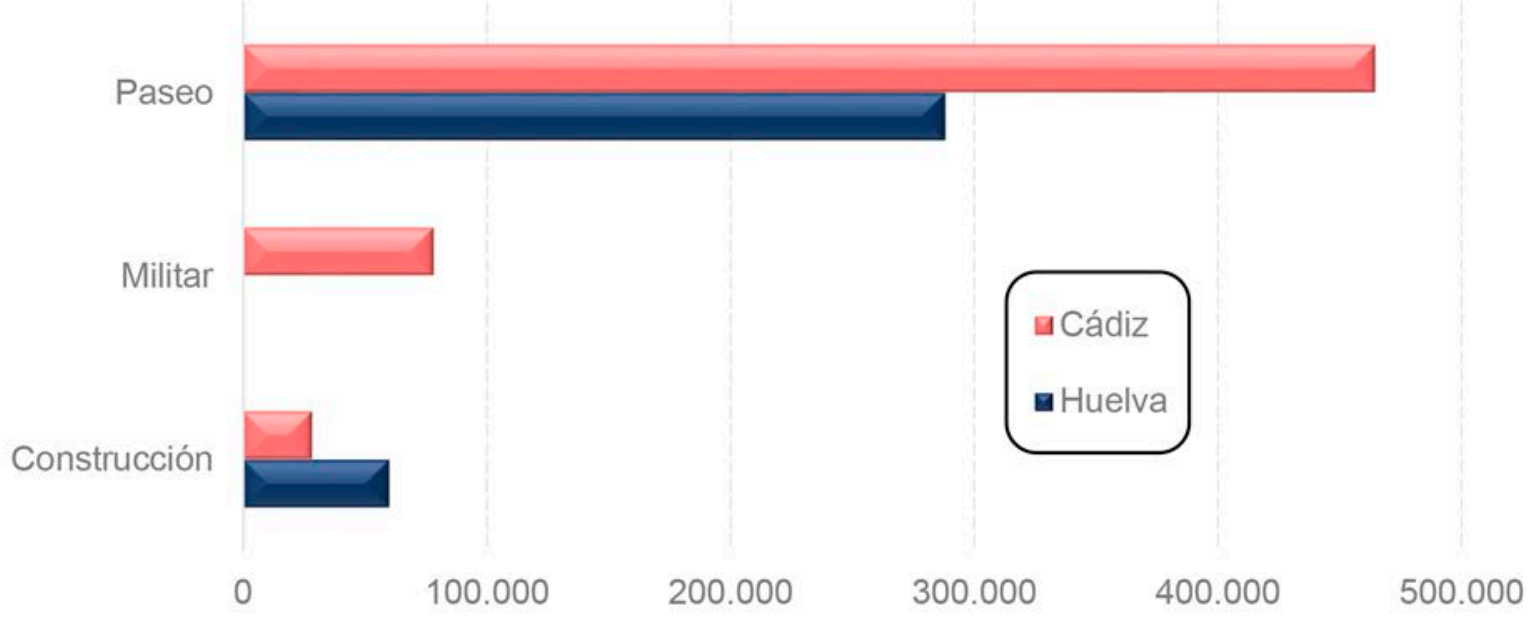

Fuente: elaboración propia

Figura 5. Capacidad de acogida de las playas de la fachada atlántica por escenario y turnos de visita ( $n^{\circ}$ de usuarios)

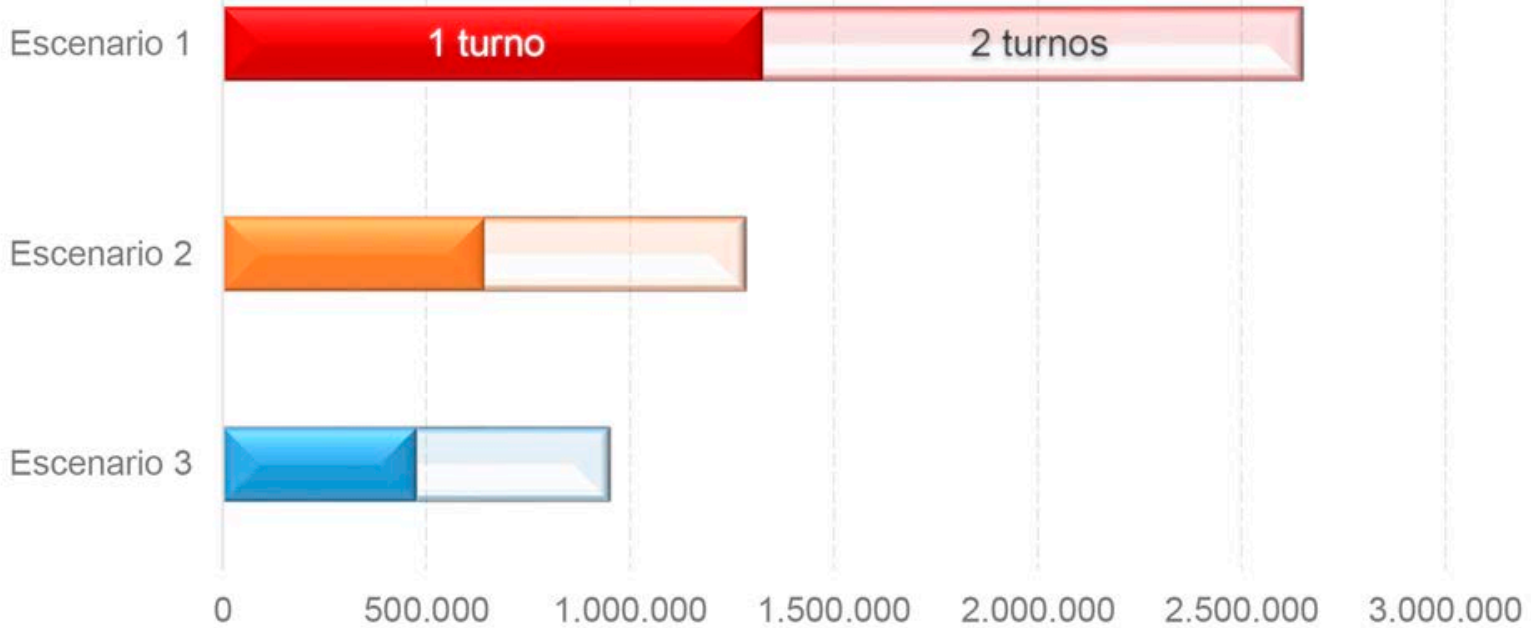

Fuente: elaboración propia 


\section{a) La provincia de Huelva}

La Figura 6 muestra el número de usuarios que las playas de la provincia de Huelva pueden acoger para cada escenario, garantizando las condiciones de salud necesarias. Se observa como el total de las playas de la provincia permite acoger a 510827 usuarios en el primer escenario, en el caso de que se organice un solo turno de visita y 1021654 usuarios si se organizan dos turnos. El número de usuarios que podría visitar la playa disminuye en el segundo escenario, alcanzando los 278898 para un solo turno y 557936 para dos. Por último, para el escenario 3, los resultados proyectan la posibilidad de acoger a un total de 222333 o 444666 usuarios según se organicen en uno o dos turnos, respectivamente.

Figura 6. Capacidad de acogida de usuarios por escenarios y turnos de las playas de la provincia de Huelva

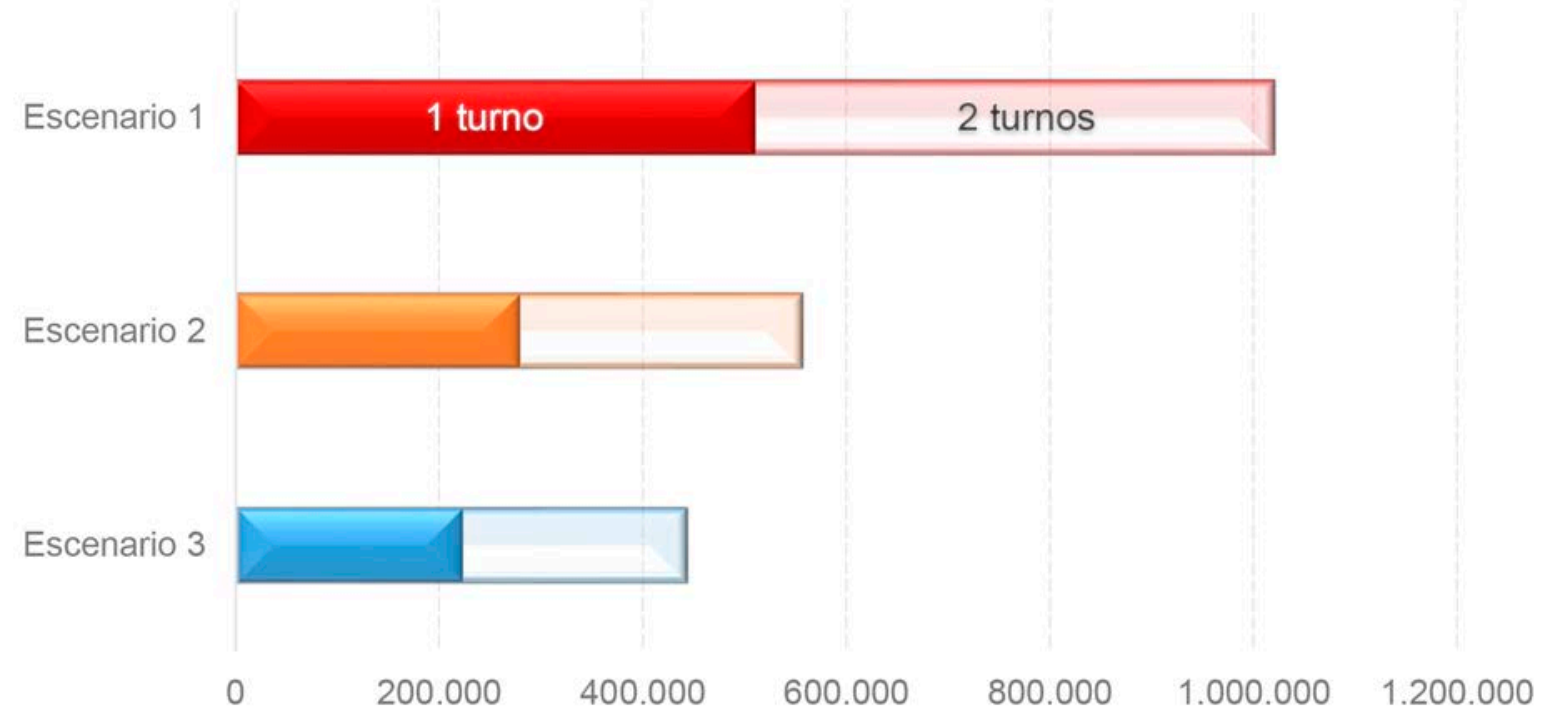

Fuente: elaboración propia

El análisis por municipios (Figura 8) muestra cómo Almonte constituye el municipio que posee mayor superficie de playa y, por tanto, a priori podría acoger a una gran cantidad de usuarios turísticos en cada escenario analizado. Ello se debe a que, a pesar de que la anchura media de las playas pocas veces supera los 25 metros, el municipio aglutina casi el 30 \% de la longitud de línea de costa de la provincia onubense.

No obstante, casi un $86 \%$ de las playas del municipio se localizan dentro del Parque Nacional y Natural de Doñana, alejadas de los puntos de acceso, con alto valor ecológico y, por lo general, bien conservadas. Estas características hacen estas playas especialmente atractivas para aquellos usuarios que, ante la situación de pandemia, buscan sentirse seguros en una playa de este tipo. 
Dado que un incremento de aforo podría ejercer una mayor presión en estos ecosistemas, se ha aplicado para estas playas una medida de ocupación por usuario dirigidas a evitar la saturación turística y garantizar un uso sostenible de la playa (15 $\mathrm{m}^{2} /$ usuario) (Roig, 2002). A pesar de la aplicación de esta medida, las playas de Almonte permitirían, en un solo turno, acoger a un total de 128578 usuarios en el escenario 1, 103544 en el escenario 2 y 97185 usuarios en el escenario 3, concentrando el $25 \%$ del total de la capacidad de acogida de las playas de la provincia. Si se aplican dos turnos, los usuarios potenciales para el escenario 1 aumentan hasta los 259 156, cifra muy superior al resto de municipios.

Seguidamente, Lepe es el municipio que posee mayor superficie de playa útil, si bien al igual que ocurre en el caso de Almonte, aunque en menor porcentaje que en éste, el $28 \%$ de las playas del municipio se caracterizan por ostentar un enorme interés ecológico. Igualmente, un elevado porcentaje de la superficie de las mismas se encuentra excluida por la presencia de construcciones sobre la playa (Figura 7), que ocupan la delimitación de Dominio Público Marítimo Terrestre establecida por la Ley 2/2013, de protección y uso sostenible del litoral.

Todo ello supone que, a pesar de que el municipio ocupa el segundo lugar según su superficie de playa, en cuanto a capacidad de acogida ocupa el cuarto lugar, permitiendo acoger en un solo turno un total de 69526 usuarios en el escenario 1 así como 35775 y 27531 usuarios en los escenarios 2 y 3, respectivamente. Esto supone el 13,4\% del total de la capacidad de acogida de las playas de la provincia.

Figura 7. Construcciones sobre la playa en el núcleo de La Antilla (Lepe, Huelva)

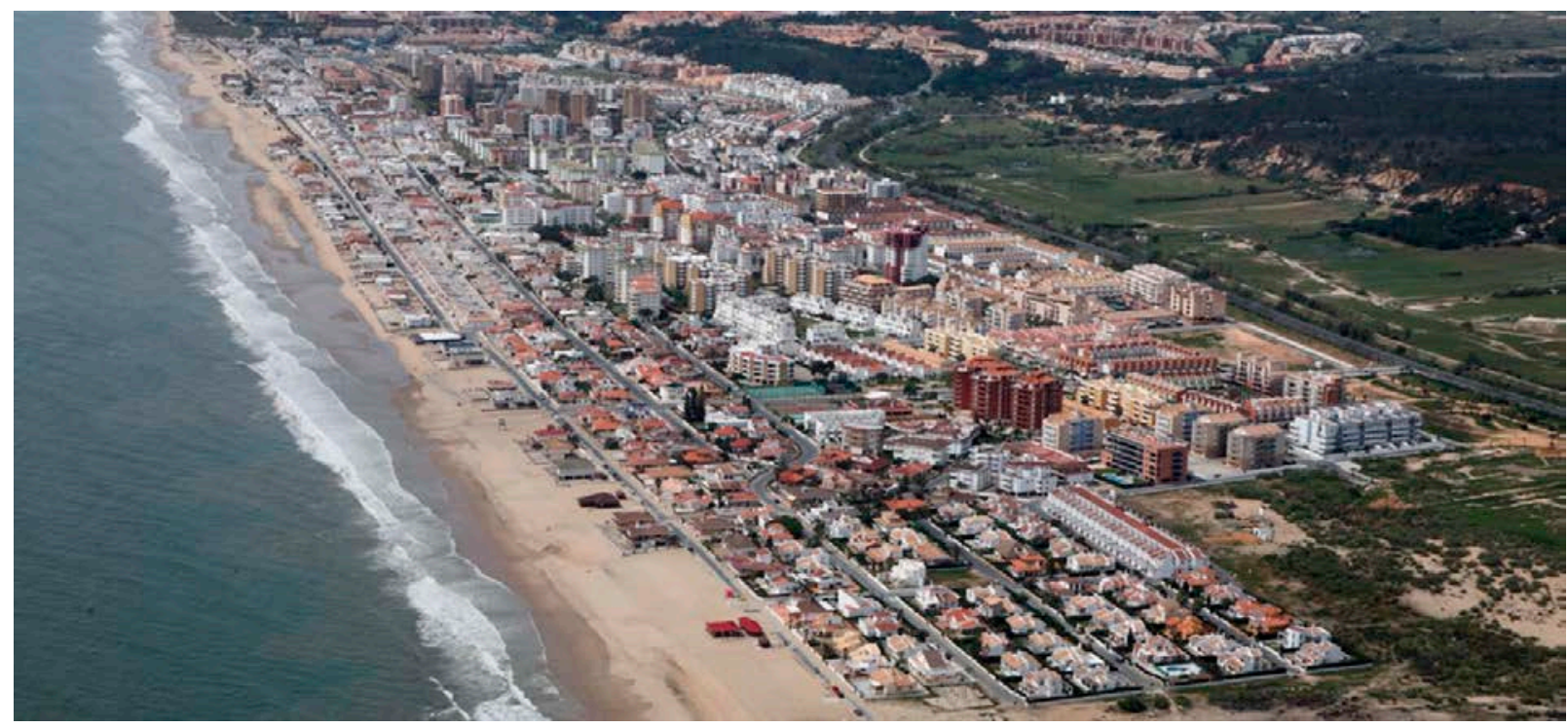

Fuente: Guía de playas del MITECO (2020) 
Figura 8. Superficie de playa total, útil y excluida y capacidad de acogida de las playas por municipio según escenario. Provincia de Huelva

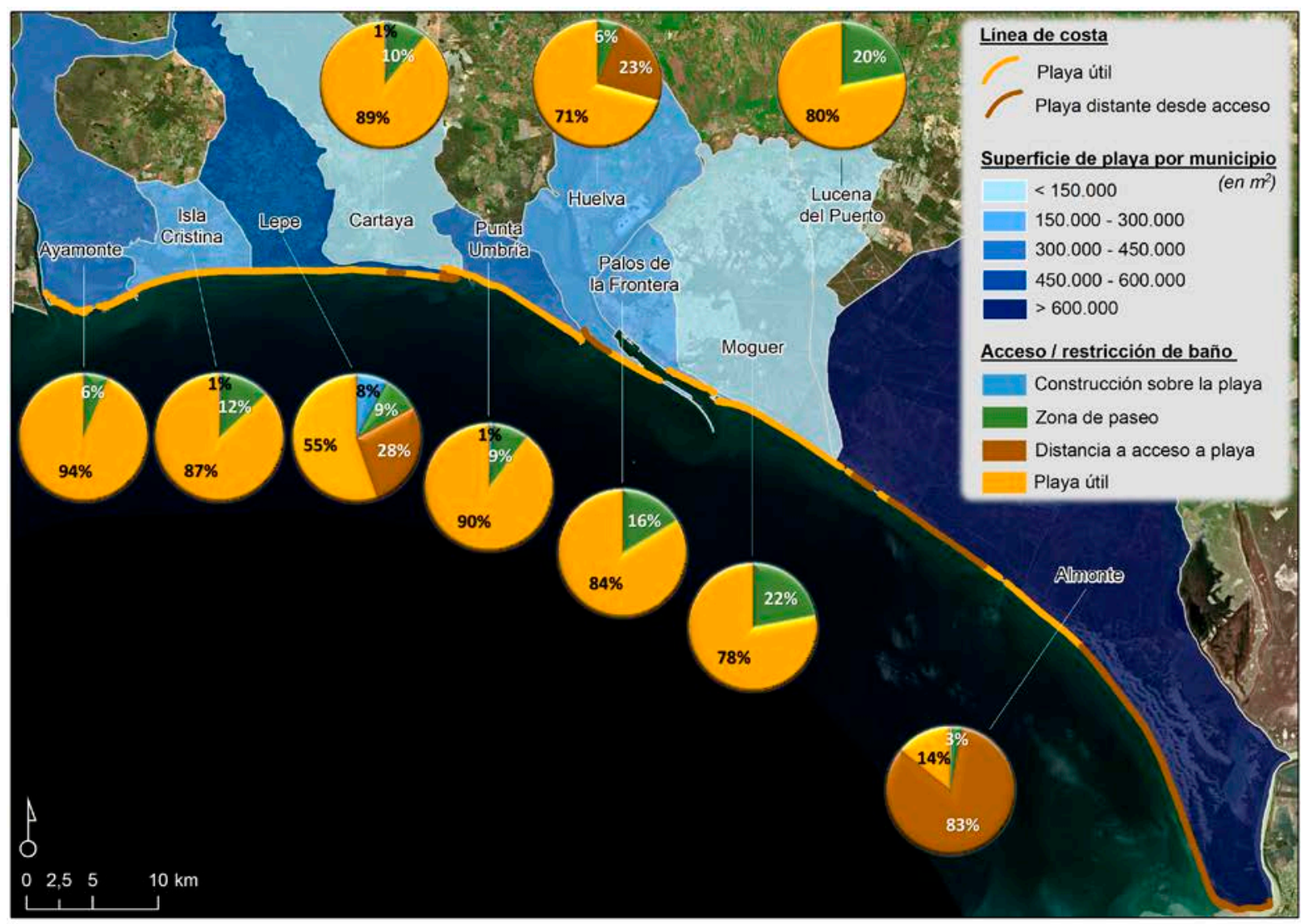

Ayamonte

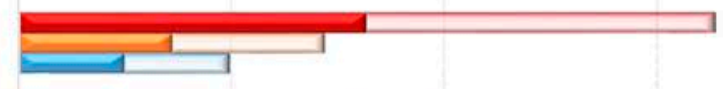

Isla Cristina
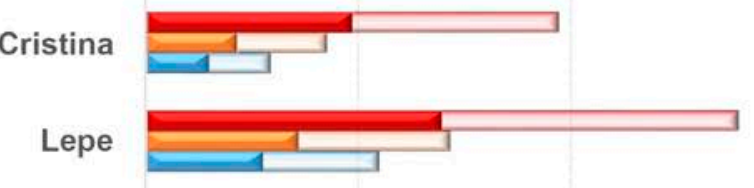

\section{Cartaya}

Punta Umbría

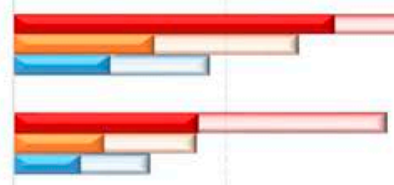

Huelva

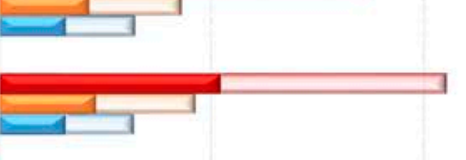

Palos de la Frontera

$$
\text { , }
$$

Lucena del Puerto

Almonte

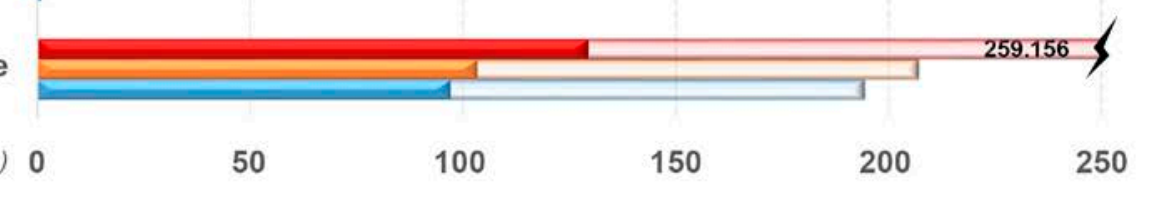

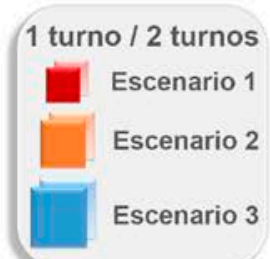

Fuente: elaboración propia 
Tras los dos ya comentados, Ayamonte, Punta Umbría e Isla Cristina son los municipios con mayor superficie de playa útil ya que, aunque presentan menor longitud de frente costero, poseen playas de gran anchura, pudiendo llegar a los 150 m en playas de Punta Umbría y hasta los $200 \mathrm{~m}$ en Ayamonte. Todo ello hace que, en cuanto a capacidad de acogida, aglutinen el 16, 15 y el 9,5\% de la capacidad de acogida de las playas de los municipios de Huelva en un solo turno, respectivamente.

El escaso frente costero y la presencia de playas de alto valor ecológico del municipio de Huelva, vinculadas al Paraje natural de los ríos Tinto y Odiel, permiten acoger a un total de 43842 usuarios en el escenario 1, 21565 usuarios en el escenario 2 y 16123 usuarios en el escenario 3, suponiendo en torno al 8,6\% de la capacidad de acogida de las playas de la provincia.

Por último, los municipios de Cartaya, Lucena del Puerto y Moguer destacan por su escasa superficie de playa útil, debido a la poca longitud de frente costero demarcado por sus límites municipales.

\section{b) La provincia de Cádiz}

Atendiendo al número de usuarios que las playas de la provincia de Cádiz pueden alojar garantizando las condiciones de seguridad necesarias (Figura 9), se observa cómo las playas de la provincia permiten acoger a un total de 815490 usuarios en el primer escenario, 364344 usuarios en el escenario 2 y 254140 usuarios en el tercero. Organizado en dos turnos de visita, los datos duplican a los expuestos.

Según la superficie de playa de la provincia de Cádiz (Figura 10), Tarifa constituye el municipio que posee mayor superficie total. Ello se debe a la presencia de un gran frente costero expuesto y a la existencia de amplias playas, alguna de las cuáles pueden alcanzar de forma puntual los 300 m de anchura. El fácil acceso a sus extensas playas justifica su destacado papel también según la superficie de playa útil. Todo ello supone que la capacidad de acogida de las playas de este municipio, al organizar los usuarios en un solo turno, alcance los 272633 usuarios en el escenario 1, 120181 usuarios en el escenario 2 y 82941 usuarios en el escenario 3, aglutinando el $33 \%$ de la capacidad de acogida de las playas de la provincia. Resulta necesario recalcar que, tanto con la aplicación de uno como de dos turnos, las playas de Tarifa doblarían la capacidad de absorción de usuarios con respecto al segundo municipio mejor situado. 
Figura 9. Capacidad de acogida de usuarios por escenarios y turnos de las playas de la provincia de Cádiz

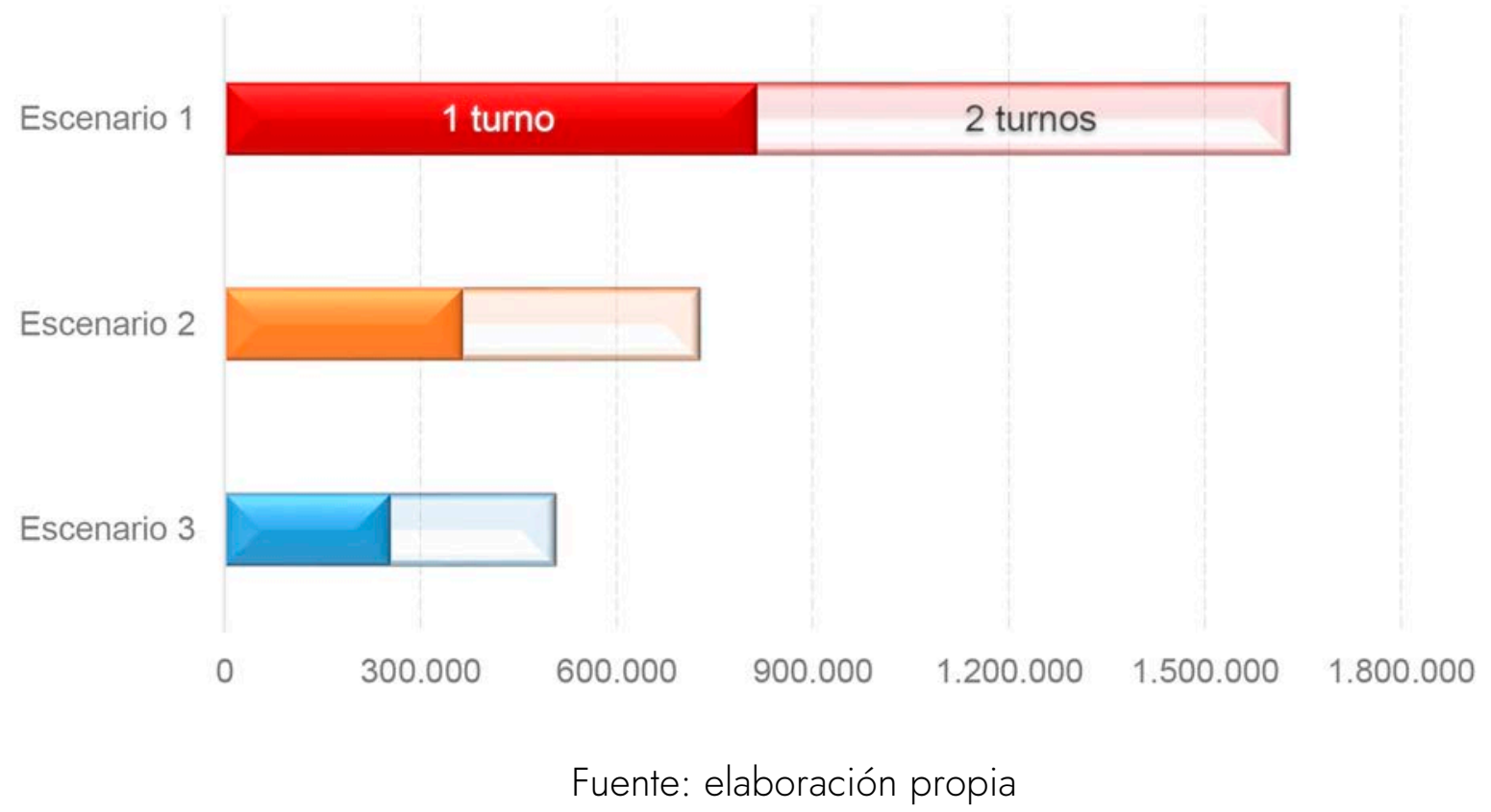

En segundo lugar, El Puerto de Santa María, al igual que en el caso de Tarifa, destaca en cuanto a superficie de playa útil y aglutina el $11,7 \%$, de la capacidad de acogida de las playas de la provincia. Conviene destacar que el municipio cuenta con playas muy extensas, a pesar de que el 14\% de las mismas se corresponden con playas de difícil acceso, originando una disminución del número de usuarios, y de la presencia de zonas de servidumbre militar.

Seguidamente, Conil de la Frontera y Barbate constituyen los municipios que disponen de mayor superficie de playa útil y aglutinan el 11,1\% y $9 \%$ de la capacidad de acogida de las playas de la provincia, respectivamente. En el caso de Cádiz, a pesar de disponer de un menor frente costero y de poseer un amplio porcentaje de playas de servidumbre militar, sus playas reúnen el $8,3 \%$ de la capacidad de acogida gracias a la anchura considerable de sus playas urbanas.

Por el contrario, los municipios de Puerto Real, Rota, San Fernando, Vejer de la Frontera y Chipiona son los que menor superficie de playa poseen y contribuyen con el $12,4 \%$ de la capacidad de acogida total. En el caso de Puerto Real $(0,4 \%)$, pese a disponer de un amplio frente costero, la mayor parte del mismo responde a sectores protegidos del oleaje (marismas). Esto supone contabilizando exclusivamente como superficie de playa pequeños sectores de acumulación artificiales (playa urbana artificial) y en la desembocadura del río San Pedro, antiguo paleocauce del río Guadalete convertido artificialmente en brazo de mar. 
Figura 10. Superficie de playa total, útil y excluida y capacidad de acogida de las playas por municipio según escenario. Provincia de Cádiz

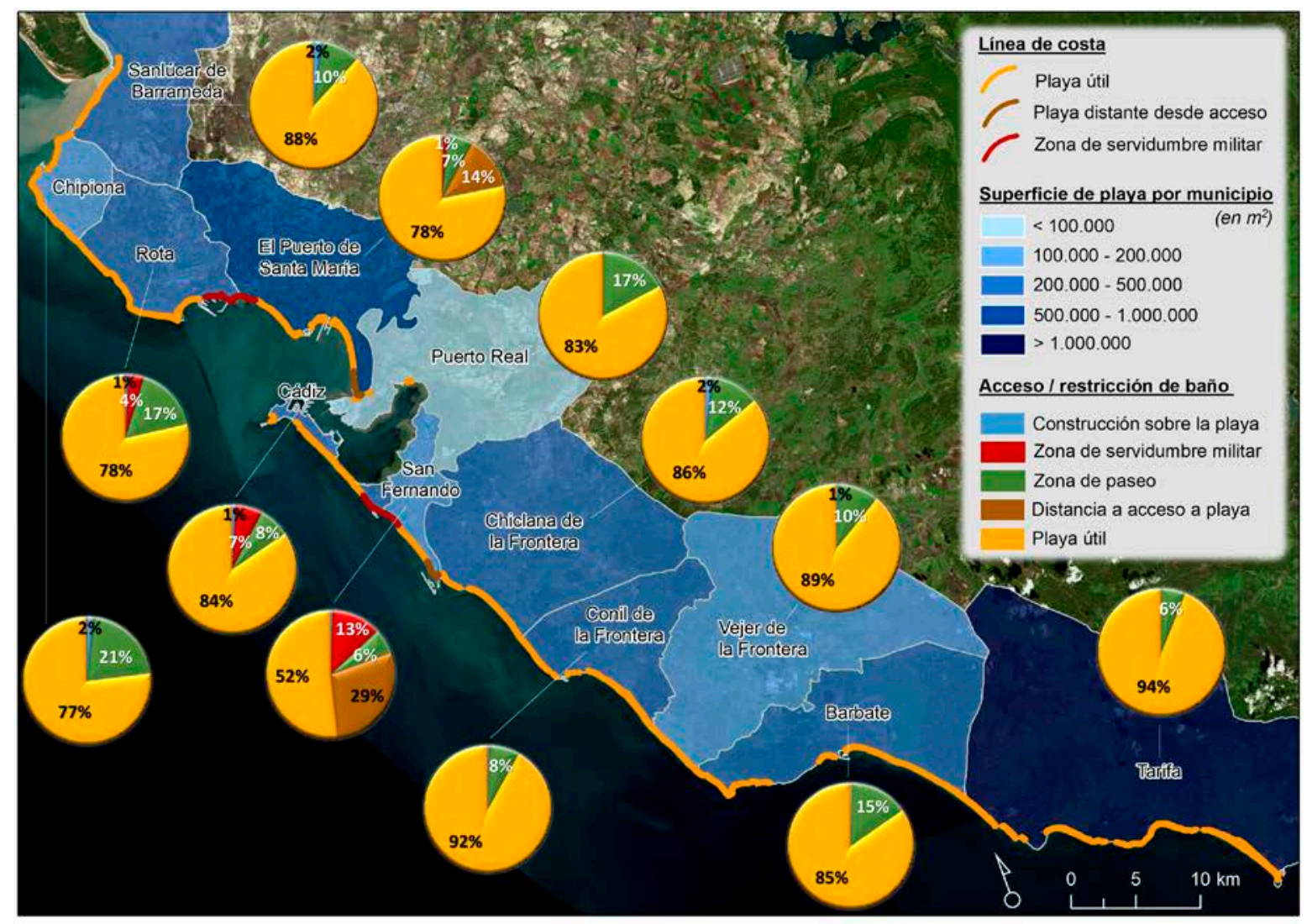

Sanlúcar de Barrameda

Chipiona

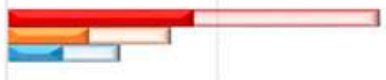

Rota

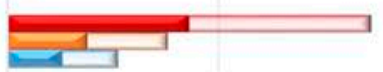

EI Puerto de Santa María

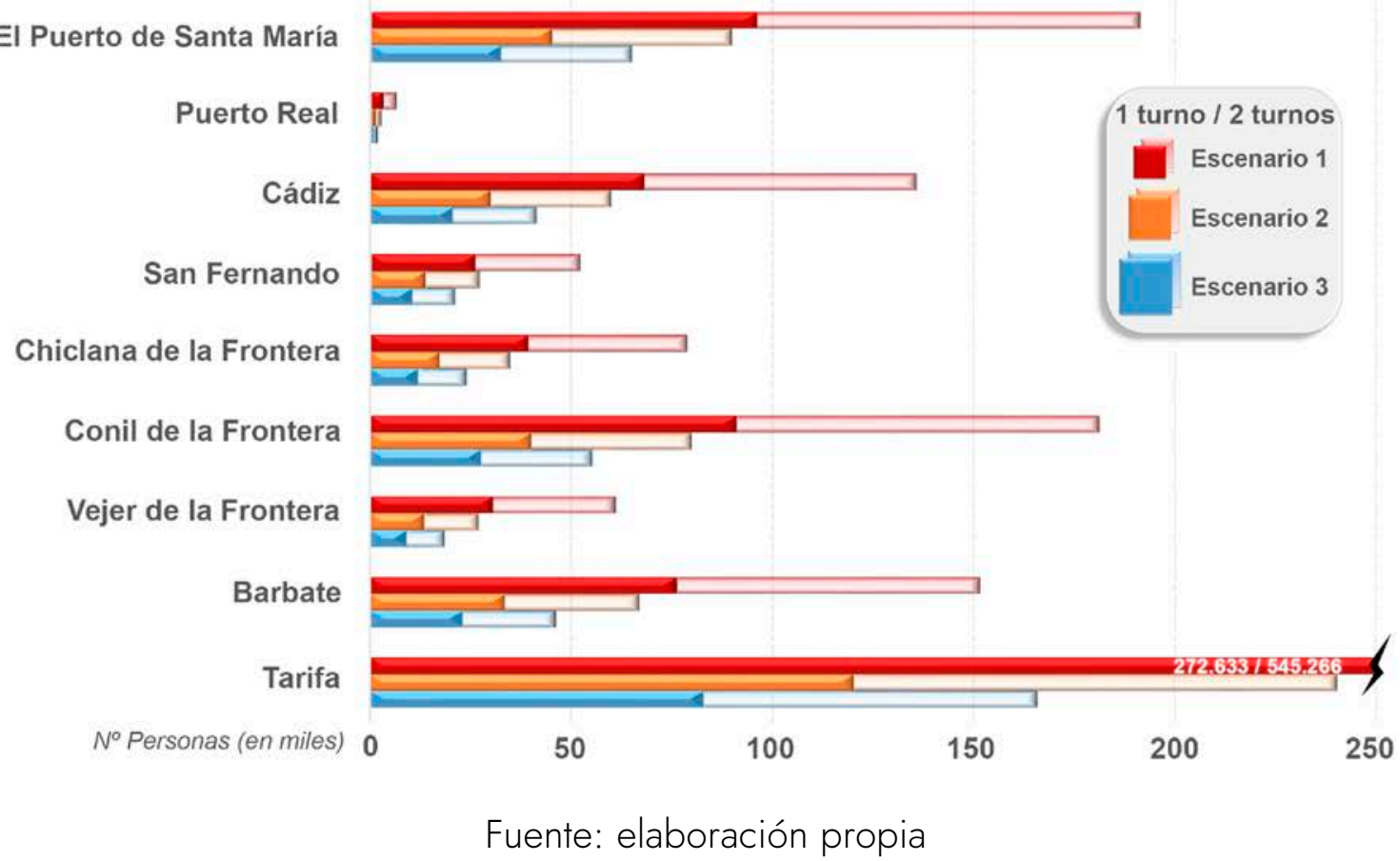

Puerto Real

Cádiz

San Fernando

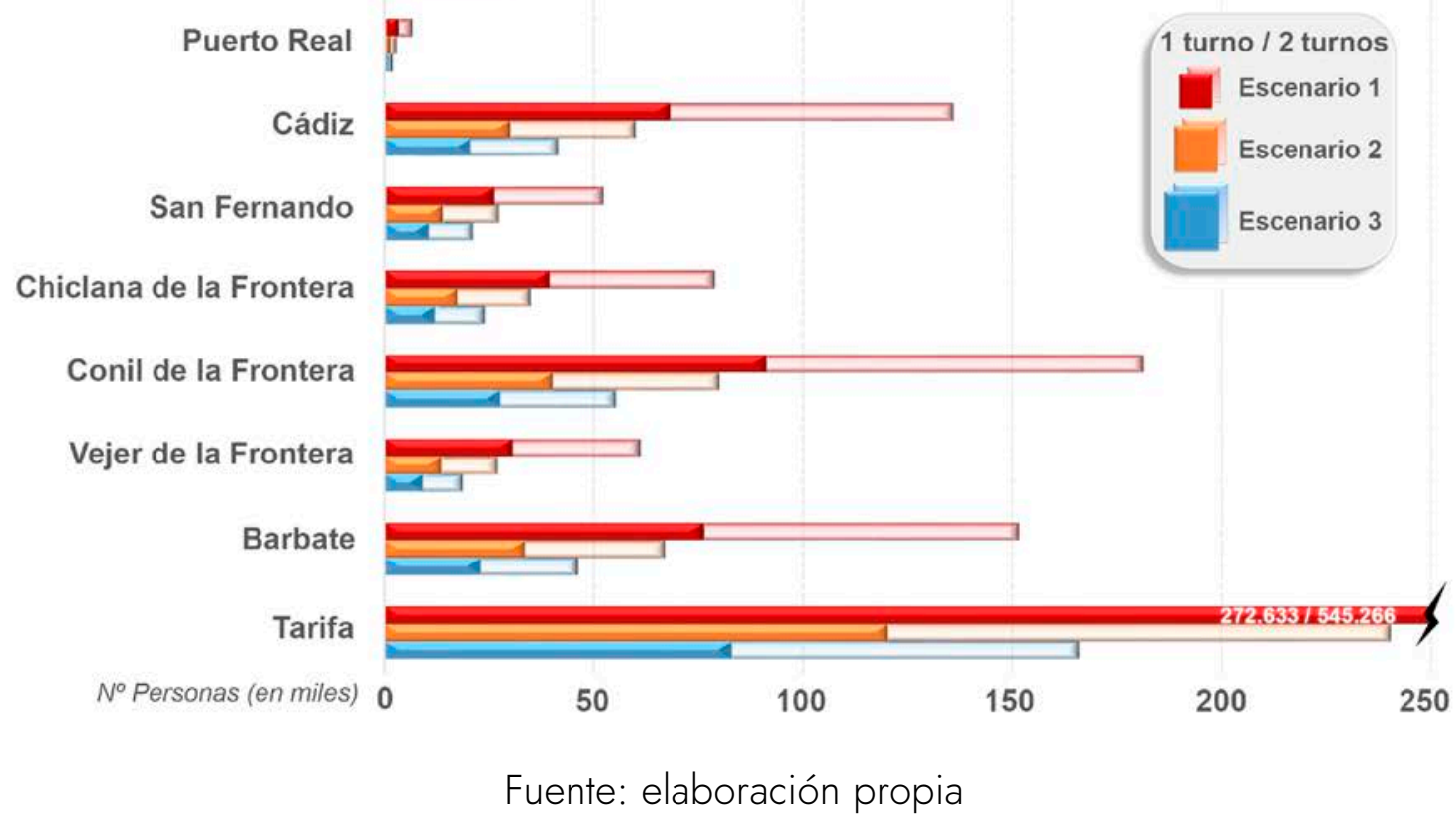

$<100.000 \quad\left(e n ~^{2}\right)$

$100.000-200.000$

$200.000-500.000$

$500.000-1.000 .000$

$>1.000 .000$

Acceso/ restricción de baño

Construcción sobre la playa

Zona de servidumbre militar

Zona de pase

Distancia a acceso a playa 
En el caso de Rota $(3,1 \%)$ y San Fernando $(3,1$ y 3,2 \%), además de poseer un escaso frente costero, gran parte de sus playas se encuentran excluidas por uso militar. Por su parte, Vejer de la Frontera (3,7\%) dispone de un limitado frente costero. En el caso de Chipiona (5,2 \%), su pequeña superficie responde a la escasa anchura media de sus playas, la mayoría de ellas afectadas por una dinámica costera muy erosiva (Del Río et al., 2019; Prieto-Campos et al., 2018).

\subsection{Valoración entre la capacidad de acogida de las playas y la demanda recreativa y turística potencial}

Con la idea de contextualizar los primeros resultados obtenidos, se realiza en este apartado una comparación entre la capacidad de acogida de las playas y sus posibles usuarios potenciales. Para ello se han calculado los datos de usuarios potenciales a partir de la recopilación de datos de población residente y de plazas turísticas (hoteles, hostales, apartamentos, campings y viviendas con fines de uso turístico (VFT), tanto rurales como urbanas) de los municipios costeros.

En general, según la aproximación realizada, la fachada atlántica posee un total de 1103505 usuarios potenciales entre población residente y plazas turísticas (Tabla 3).

Tabla 3. Capacidad de acogida para cada escenario y potenciales usuarios de las playas de la fachada atlántica

\begin{tabular}{|c|c|c|c|c|c|c|}
\hline Escenario & $\begin{array}{c}\mathrm{N}^{\circ} \\
\text { turnos }\end{array}$ & Capacidad & $\begin{array}{l}\text { Población } \\
\text { residente }\end{array}$ & $\begin{array}{l}\text { Plazas } \\
\text { turísticas }\end{array}$ & $\begin{array}{l}\text { Plazas } \\
\text { VFT }\end{array}$ & Total \\
\hline \multirow{2}{*}{1} & 1 & 1326317 & \multirow{6}{*}{927735} & \multirow{6}{*}{108045} & \multirow{6}{*}{67725} & \multirow{6}{*}{1103505} \\
\hline & 2 & 2652634 & & & & \\
\hline \multirow{2}{*}{2} & 1 & 643312 & & & & \\
\hline & 2 & 1286624 & & & & \\
\hline \multirow{2}{*}{3} & 1 & 476473 & & & & \\
\hline & 2 & 952946 & & & & \\
\hline
\end{tabular}

Fuente: elaboración propia a partir de datos del Sistema de Información Multiterritorial de Andalucía (2019) y del Registro de Turismo de Andalucía (2020) 
Los datos reflejan que, para un solo turno, el escenario 1 es capaz de absorber la totalidad de los usuarios. No obstante, los escenarios 2 y 3 no tendrían capacidad de acogida suficiente para albergar a la población residente en un solo turno. Mientras que el establecimiento de dos turnos en el escenario 2 podría acoger a todos los usuarios potenciales, el escenario 3 no podría acoger ni siquiera a la totalidad de la población residente.

a) La provincia de Huelva

La provincia de Huelva dispone de 365489 potenciales usuarios de playas, todos ellos con posibilidad de ser acogidos en un solo turno en los escenarios 1 y 2 (Tabla 4). Para el caso del escenario 3, el establecimiento de un solo turno podría alojar a 222333 usuarios (el 61,5\% de los usuarios potenciales).

Tabla 4. Capacidad de acogida para cada escenario y potenciales usuarios de las playas de la provincia de Huelva

\begin{tabular}{|c|c|c|c|c|c|c|}
\hline Escenario & $\begin{array}{c}\mathrm{N}^{\circ} \\
\text { turnos }\end{array}$ & Capacidad & $\begin{array}{l}\text { Población } \\
\text { residente }\end{array}$ & $\begin{array}{l}\text { Plazas } \\
\text { turísticas } \\
\text { regladas }\end{array}$ & $\begin{array}{c}\text { Plazas } \\
\text { VFT }\end{array}$ & Total \\
\hline \multirow{2}{*}{1} & 1 & 510827 & \multirow{6}{*}{309459} & \multirow{6}{*}{46489} & \multirow{6}{*}{9541} & \multirow{6}{*}{365489} \\
\hline & 2 & 1021654 & & & & \\
\hline \multirow{2}{*}{2} & 1 & 278898 & & & & \\
\hline & 2 & 557936 & & & & \\
\hline \multirow{2}{*}{3} & 1 & 222333 & & & & \\
\hline & 2 & 444666 & & & & \\
\hline
\end{tabular}

Fuente: elaboración propia a partir de datos del Sistema de Información Multiterritorial de Andalucía (2019) y del Registro de Turismo de Andalucía (2020)

La distribución municipal de los potenciales usuarios turísticos muestra como la capitalidad de Huelva hace que sea el municipio que más usuarios aporta (Figura 11 y Anexo II). No es el caso si contemplamos el número de plazas turísticas, donde los municipios de Moguer e Isla Cristina son los que encabezan la lista, debido a la presencia de grandes campings que incorporan 8895 y 5374 plazas, respectivamente.

El análisis por escenarios a escala municipal (Figura 12) muestra, para un turno, cómo las playas de los municipios de Huelva, Moguer, Lucena del Puerto y Cartaya ni siquiera podrían alojar su 
demanda municipal potencial en el escenario más permisivo (escenario 1). Ello implicará un desplazamiento de esta demanda a los municipios colindantes, incrementando la presión sobre los mismos. A estos municipios se suma en los escenarios 2 y 3 las playas del municipio de Isla Cristina, que en un solo turno no podría alojar al $100 \%$ de los usuarios potenciales.

Igualmente ocurre para el escenario 3 en las playas de Ayamonte y Lepe. Sólo playas de los municipios de Almonte y Punta Umbría podrían acoger la totalidad de los usuarios potenciales en los tres escenarios.

Figura 11. Potenciales usuarios en los municipios de la provincia de Huelva

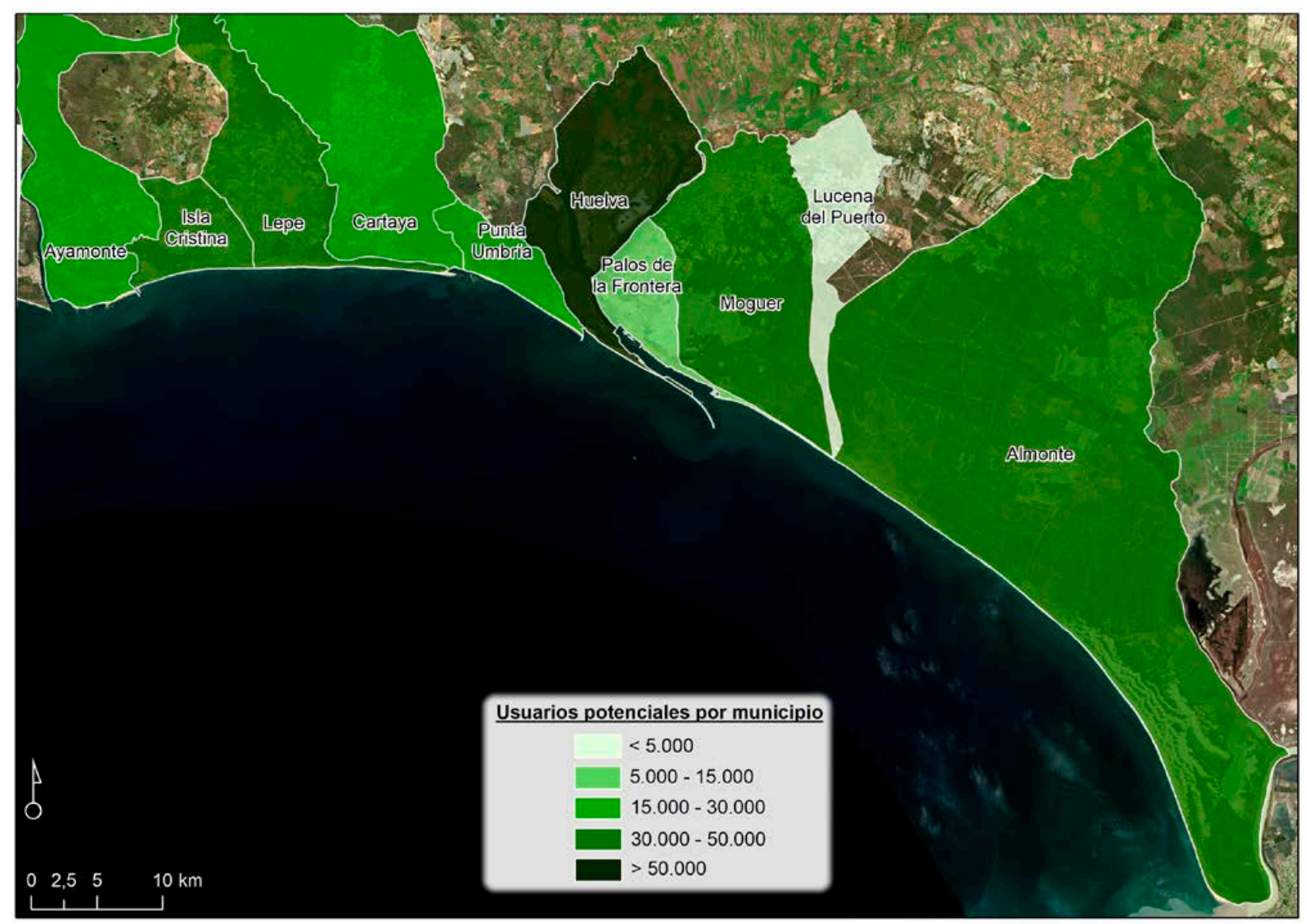

Fuente: elaboración propia a partir de datos del Sistema de Información Multiterritorial de Andalucía (2019) y del Registro de Turismo de Andalucía (2020) 
Figura 12. Capacidad de acogida en cada escenario menos usuarios potenciales (residentes y plazas turísticas). Provincia de Huelva

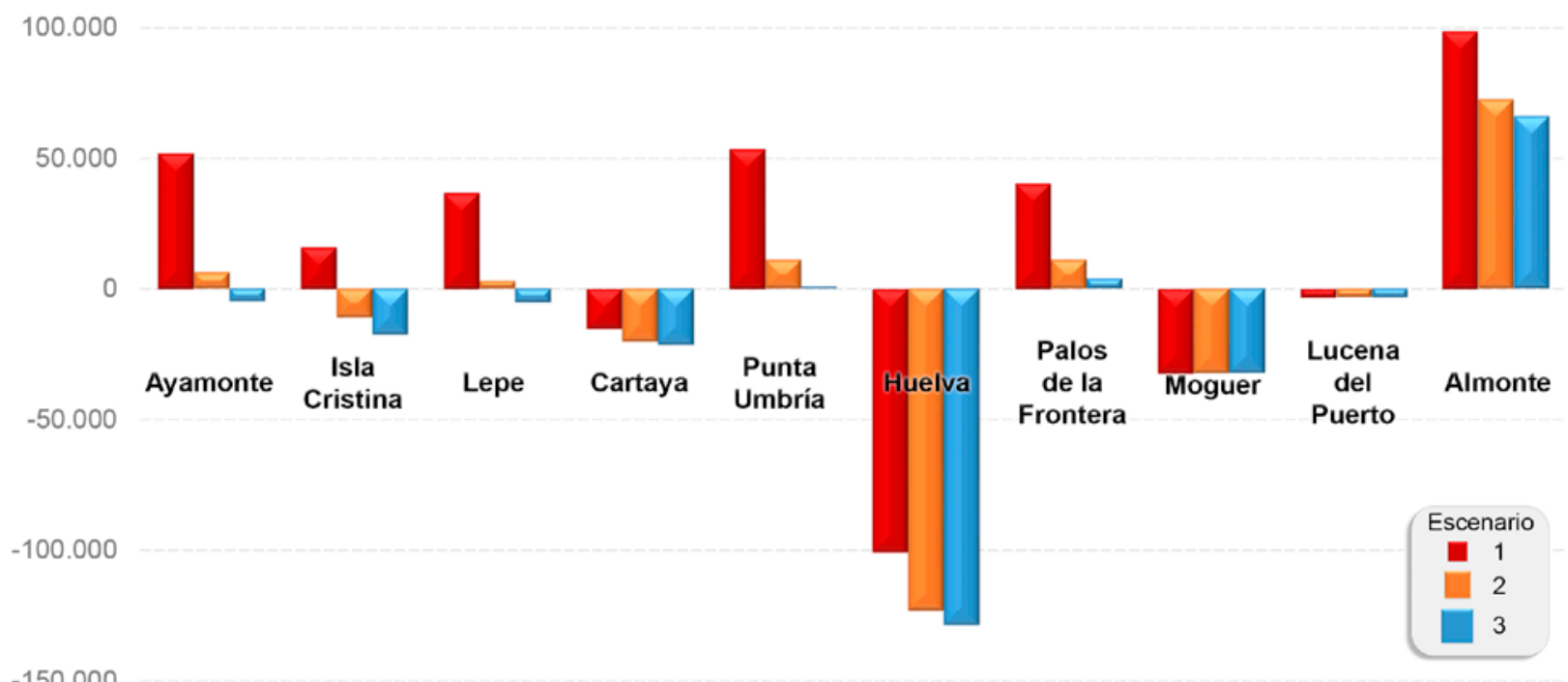

Fuente: elaboración propia

b) La provincia de Cádiz

La provincia de Cádiz duplica el número de potenciales usuarios de playas registrado para la provincia de Huelva, un total de 738 016, con posibilidad de ser acogidos en su totalidad en un turno para el escenario 1 (Tabla 5). Para el caso de los escenarios 2 y 3 , el establecimiento de un solo turno ni siquiera podría alojar a la totalidad de la población residente.

La distribución municipal de los usuarios potenciales (Figura 13 y Anexo II) muestra un alto número de plazas turísticas asociadas tanto a la capitalidad del municipio de Cádiz, como de uno de los principales destinos de la provincia: Chiclana de la Frontera. Destacan las elevadas tasas de plazas turísticas de Conil de la Frontera y Tarifa, que disponen de amplios campings con capacidad para 7000 y 5000 usuarios, respectivamente.

El análisis por escenarios (Figura 14) muestra cómo, en un solo turno, sólo las playas de Tarifa seguirán teniendo capacidad de absorción de usuarios de otros municipios una vez satisfecha su propia demanda en todos los escenarios. Por su parte, las playas del municipio de Barbarte sólo podrían alojar a la totalidad de los usuarios potenciales en el primer y segundo escenario.

Para un solo turno, las playas de Sanlúcar de Barrameda, El Puerto de Santa María, Puerto Real, Cádiz, San Fernando y Chiclana de la Frontera no podrían alojar su demanda residente potencial en el escenario 1, mientras que las playas de los municipios de Rota, Conil de la Frontera y Vejer 
de la Frontera sólo podrían satisfacer la demanda potencial de residentes en estos municipios en el primer escenario.

Tabla 5. Capacidad de acogida para cada escenario y potenciales usuarios de las playas de la provincia de Cádiz

\begin{tabular}{|c|c|c|c|c|c|c|}
\hline Escenario & $\begin{array}{l}\mathrm{N}^{\circ} \\
\text { turnos }\end{array}$ & Capacidad & $\begin{array}{l}\text { Población } \\
\text { residente }\end{array}$ & $\begin{array}{l}\text { Plazas } \\
\text { turísticas } \\
\text { regladas }\end{array}$ & $\begin{array}{l}\text { Plazas } \\
\text { VFT }\end{array}$ & Total \\
\hline \multirow{2}{*}{1} & 1 & 815490 & \multirow{6}{*}{618216} & \multirow{6}{*}{61556} & \multirow{6}{*}{58184} & \multirow{6}{*}{738016} \\
\hline & 2 & 1630098 & & & & \\
\hline \multirow{2}{*}{2} & 1 & 363344 & & & & \\
\hline & 2 & 726688 & & & & \\
\hline \multirow{2}{*}{3} & 1 & 254140 & & & & \\
\hline & 2 & 508280 & & & & \\
\hline
\end{tabular}

Fuente: elaboración propia a partir de datos del Sistema de Información Multiterritorial de Andalucía (2019) y del Registro de Turismo de Andalucía (2020)

Figura 13. Potenciales usuarios en los municipios de la provincia de Cádiz

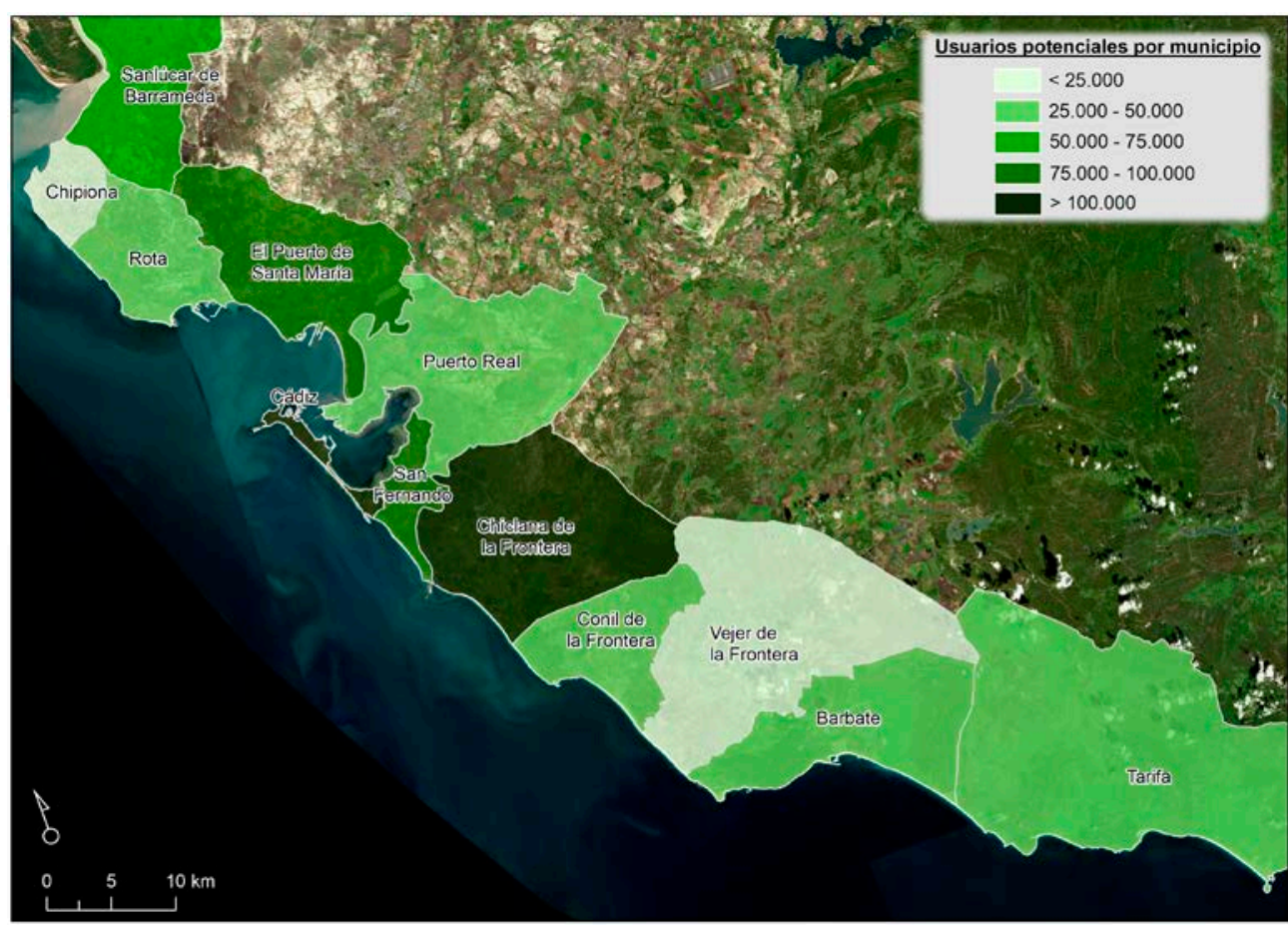

Fuente: elaboración propia a partir de datos del Sistema de Información Multiterritorial de Andalucía (2019) y del Registro de Turismo de Andalucía (2020) 
Figura 14. Capacidad de acogida en cada escenario menos usuarios potenciales (residentes y plazas turísticas). Provincia de Cádiz

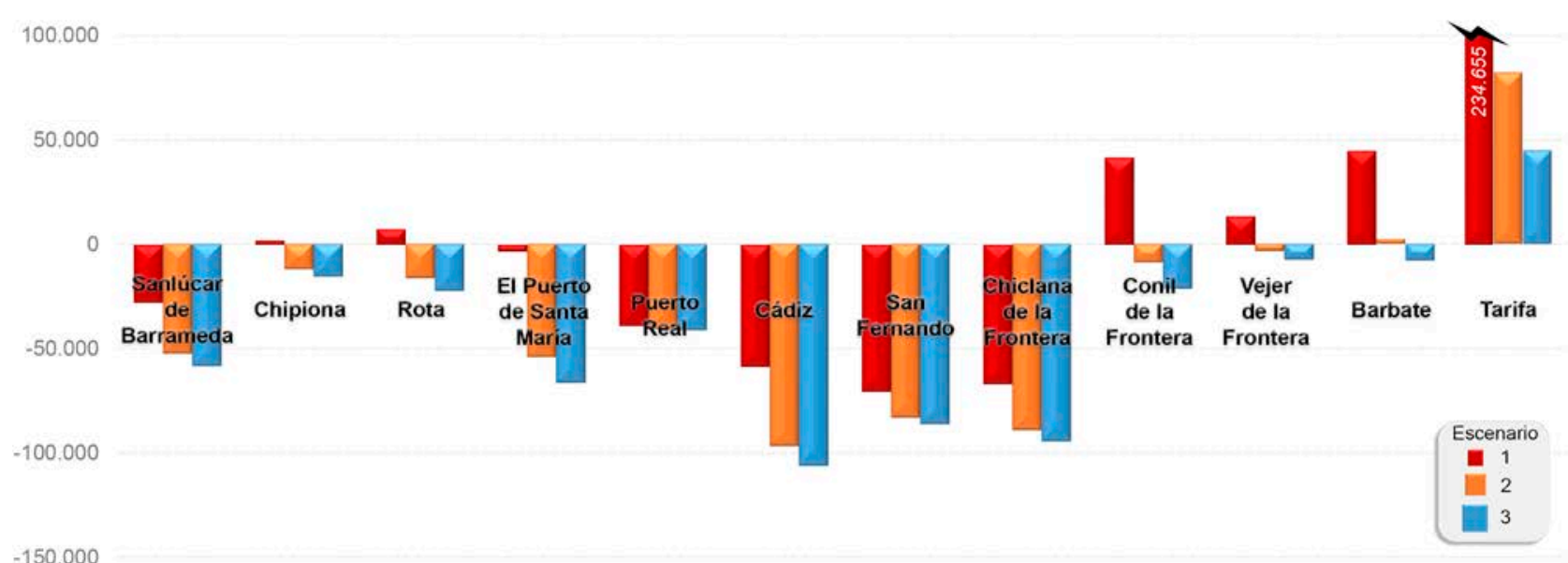

Fuente: elaboración propia

\section{Discusión}

La situación actual de pandemia producida por la COVID-19 y los intentos por salvar la temporada turística han puesto de manifiesto la necesidad de realizar mediciones de capacidad de acogida de las playas. De este modo, frente a una medición de capacidad de carga, que surge con el interés primordial de garantizar una explotación sostenible de la playa como recurso turístico, surgen actualmente aproximaciones a la medición de la capacidad de acogida de playas dirigida a garantizar su explotación segura desde el punto de vista sanitario. Ello incluye también evitar la saturación turística.

La situación sorprendió a las autoridades de los países mediterráneos europeos al inicio de la temporada turística con la necesidad de controlar el aforo y evitar aglomeraciones, pero sin contar con una base clara de cuál debe ser el número de usuarios posibles.

El presente trabajo supone una contribución a este problema, si bien diversos aspectos sobre la metodología y los resultados merecen ser discutidos.

Respecto a la metodología, es necesario resaltar que las playas, tanto su superficie emergida como submarina, son unidades geomorfológicas que presentan una gran variabilidad inter e intraanual. Esta variabilidad se acentúa en el litoral atlántico, el cual se caracteriza por una dinámica mesomareal, un amplio fetch, una potente deriva litoral y una plataforma litoral extensa y de escasa pendiente que puede afectar a la delimitación de la pleamar (Crowell et al., 1991; Zhang et al., 2002; Moore et al., 2006; Ruggiero \& List, 2009). Por ello, los indicadores han 
sido fotointerpretados y digitalizados según la última ortofotografía disponible (2016), la cual fue obtenida en época estival, coincidiendo con el perfil de calma de la playa y, a su vez, con la temporada turística. Constituye ésta, por tanto, la mejor aproximación a la superficie de playa existente a escala regional. No obstante, este primer análisis necesita completarse con una aproximación más detallada a nivel municipal e incluso de playa, que debe tener en cuenta otros factores.

De igual modo, la obtención de la anchura de la playa seca, además de su gran importancia como recurso turístico, constituye por sí mismo otro indicador que cuantifica la anchura lineal de la playa útil y describe de manera más completa la situación de la playa, al ser resultado del análisis conjunto de los indicadores anteriores (Díaz-Cuevas et al., 2020b). Su uso y potencialidades para analizar la dinámica de las playas deberán ser estudiados en un futuro.

En otro orden de cosas, es necesario resaltar que si bien, para el cálculo de la playa útil se han excluido zonas en base a una serie de criterios (ocupación -construcciones sobre la playa que impiden su uso por parte de los usuarios-, recreativo (franja de $4 \mathrm{~m}$ desde la línea de pleamar destinada a paseos y zona de entrada y salida al mar) y de uso restringido (zonas de servidumbre militar), en este trabajo se ha tenido en cuenta como playa útil toda la superficie de la playa seca, aunque normalmente los usuarios se sitúan en el área de exposición solar, cercana al mar, pero sin atravesar la zona de paseo.

Del mismo modo, ha de tenerse en cuenta que existen playas en al ámbito de estudio que superan los 200 m de anchura y que, por lo general, el usuario descarta en condiciones normales la localización en áreas muy alejadas del mar.

En relación a los cálculos de superficie de playa por usuario, es preciso comentar la gran variabilidad existente en su determinación. Las aproximaciones realizadas por algunos ayuntamientos, como por ejemplo las experiencias ya comentadas de Vélez-Málaga y Sanxenxo, determinan cuadrículas de superficie de playa inferiores a las contempladas por algunos autores para garantizar un uso sostenible de ésta y evitar su saturación turística. En este sentido, los autores, en el momento de realización de este trabajo, sólo han encontrado la referencia de Botero et al. (2020). Ello se debe a la gran incertidumbre existente en cuanto a la determinación de la distancia de seguridad. Desde el punto de vista sanitario, esta oscila entre los 1,5 y los 2 metros. A pesar de esta incertidumbre, la determinación de esta distancia es clave para calcular el aforo permitido de la playa. De hecho, tal y como señala Yepes (2020) con el dato de aforo 
permitido, cualquier aplicación en tiempo real podría ser capaz de comunicar a los usuarios si se ha desbordado el límite seguro de uso de una playa.

Por ello y ante la incertidumbre generada, se ha renunciado en este trabajo a realizar una única aproximación, y se han abordado tres escenarios diferentes basados en la aplicación de diferentes superficies de playa útil por usuario. Igualmente, se ha determinado la capacidad en función del establecimiento de uno o dos turnos.

De forma generalizada, los resultados muestran una alta capacidad de las playas atlánticas andaluzas para acoger usuarios en condiciones de seguridad necesarias. Estas cifras varían entre los 2652634 usuarios en el caso más permisivo (escenario 1 y dos turnos) y 476473 usuarios en el caso más restrictivo (escenario 3 y un turno). Por municipios, destaca la gran capacidad de acogida de las playas de los municipios de Tarifa (Cádiz), que aglutina el 21 \% del total de la capacidad de las playas atlánticas, de Almonte (Huelva), con aproximadamente el $10 \%$ de la capacidad total y de El Puerto de Santa María (Cádiz), con un 7,2\%.

Con idea de contextualizar los resultados obtenidos, se ha realizado una valoración de los potenciales usuarios (asociados a residentes y a plazas turísticas) de las playas analizadas. Los resultados, vinculados a una primera aproximación, muestran que la fachada atlántica posee 1103505 usuarios potenciales, cuya totalidad, para un turno solo podrían ser acogidos en el escenario 1. En los escenarios 2 y 3 ni siquiera habría capacidad de acogida suficiente para albergar a la población residente para un solo turno.

El análisis por provincias muestra cómo las playas de la provincia de Huelva poseen mayor capacidad que las de la provincia de Cádiz para acoger a la totalidad de los usuarios turísticos. No obstante, el análisis municipal revela otros aspectos claves. Así, para un solo turno, las playas de cuatro de los diez municipios de la provincia de Huelva (Huelva, Moguer, Lucena del Puerto y Cartaya) ni siquiera podrían alojar su demanda municipal potencial de población residente en el escenario 1, fenómeno que ocurre también en las playas de seis de los doce municipios de la provincia de Cádiz (Sanlúcar de Barrameda, El Puerto de Santa María, Puerto Real, Cádiz, San Fernando y Chiclana de la Frontera). Ello implicará un desplazamiento de esta demanda sobrante a los municipios colindantes, incrementando la presión sobre los mismos.

Generalmente, los resultados son verificados por comparación con otros estudios realizados en la zona. Sin embargo, según el conocimiento de los autores, salvo las experiencias ya comentadas llevadas a cabo por algunos ayuntamientos, ningún trabajo ha sido realizado hasta este momento. Sí que se han diseñado metodologías para ser aplicadas a nivel de playa 
individual (Yepes, 2020), que requieren de la disposición de múltiples variables que han de ser tenidas en cuenta a escala de playa individual. Entre estas variables, Yepes incorpora el establecimiento de una distancia de seguridad sanitara y, por tanto, de una superficie de playa útil por usuario. Efectivamente, en todo estudio de este tipo que se refiera al sector turístico, las zonas costeras y la salud pública requieren de gran cantidad de información detallada. Sin embargo, además de la incertidumbre existente sobre aspectos tan claves como la distancia de seguridad, la disponibilidad de datos para los diferentes sectores costeros o regiones varía enormemente. Es aquí donde se enmarca el presente trabajo, como una primera aproximación que ayuda a los planificadores para asignar recursos y determinar dónde centrar los análisis posteriores. De esta manera, también ayudaría a investigar y determinar otras variables que son costosas y difíciles de obtener para ser aplicadas a grandes áreas.

Matizar los resultados obtenidos resulta también necesario. De este modo, es preciso tener en cuenta que no todos los usuarios van todos los días a la playa, así como que existen otros usuarios (visitantes que no pernoctan) que no están siendo tenidos en cuenta entre los posibles usuarios.

Igualmente, el número de usuarios posibles también deberá tener en cuenta la disponibilidad de aparcamientos, la capacidad de atención sanitaria, el uso de la superficie marina, etc. No obstante, estos elementos escapan al objetivo planteado y deberán tenerse en cuenta en análisis más detallados llevados a cabo por las propias administraciones locales.

Este es el motivo por el que estas aproximaciones se han llevado a cabo a escala municipal, con idea de ayudar a la toma de decisiones. En este sentido, son los gestores locales los que deben tomar las decisiones en estos momentos de crisis, asegurando, tal y como afirman Botero et al. (2020), que la COVID-19 no finalice sino fortalezca el turismo de sol y playa y lo haga evolucionar hacia un uso adecuado.

Es aquí donde se enmarca este trabajo, pues pese que en él se abordan las bases, son las administraciones locales, en última instancia, las responsables de anticiparse a los posibles escenarios y actuar en consecuencia. Por todo ello, es necesario insistir en la importancia crítica de una buena previsión a nivel municipal, que supere el tratamiento de la playa como un mero arenal y tenga en cuenta otras cuestiones clave. 


\section{Conclusiones}

La aproximación a la capacidad de carga física de las playas siempre ha derivado en un gran interés por parte de diferentes autores que han realizado diversas aproximaciones para su medición. Este interés se ha visto incrementado con la actual situación originada por la pandemia del coronavirus, que aconseja, si no obliga, a determinar la capacidad de acogida de usuarios de las playas para aprovechar la temporada turística de sol y playa con garantías de calidad sanitarias.

Es aquí donde se inserta el pretende trabajo desarrollado con el fin de abordar y contribuir para enfrentar la necesidad que tienen los gestores de los ayuntamientos costeros de ordenar sus playas ante la amenaza de propagación de la COVID-19 y, por ende, para asegurar su disfrute por parte de los usuarios.

En el presente trabajo se realiza una primera aproximación de la capacidad de las playas atlánticas andaluzas para absorber la demanda recreativa y turística. Se construyen tres escenarios de ocupación en función de la superficie de playa útil por usuario y del establecimiento de uno o dos turnos de visita.

Los resultados muestran como el escenario 1, menos restrictivo, podría acoger en un solo turno a la totalidad de los usuarios potenciales. El escenario 2 sólo podría acoger a todos los usuarios mediante el establecimiento de dos turnos y en el escenario 3, ni con el establecimiento de dos turnos se podría acoger a los residentes.

Si bien los resultados son matizables, debido a la gran incertidumbre existente acerca de las medidas correctas y deben ser completados con análisis a escalas más detalladas, suponen una necesaria primera aproximación que puede resultar de utilidad para la toma de decisiones.

Agradecimientos: Este trabajo se enmarca en el proyecto de investigación "Inteligencia Territorial Vs. Crecimiento Turístico. La Planificación y Gestión de Destinos ante el Nuevo Ciclo Expansivo Inmobiliario" (Ref. PGC2018-095992-B-I00), financiado por el Ministerio de Ministerio de Ciencia, Innovación y Universidades.

Declaración responsable: Las/os autoras/es declaran que no existe ningún conflicto de interés con relación a la publicación de este artículo. Las tareas asociadas a este trabajo se han distribuidos de forma equitativa trabajando especialmente la revisión, contextualización y redacción de este Pilar Díaz y el levantamiento de información y la cartografía Antonio Prieto. El resto de tareas se han compartido al $50 \%$. 


\section{Bibliografía}

Betancourt, L., \& Herrera-Moreno, A. (2005). Acerca de la capacidad de carga física de Playa Grande, Cayo Levantado, Samaná, República Dominicana (República de Santo, Santo Domingo: Reporte Técnico del Programa EcoMar). Retrieved from https://programaecomar.webs.com/CayoLevantado.pdf

Botero, C.M., Mercadé, S., Cabrera, J.A., \& Bombana, B. (2020). El turismo de sol y playa en el context de la COVID-19. Escenarios y recomendaciones. Santa Marta: Red Iberoamericana de Gestión y Certificación de Playas - PROPLAYAS.

Butler, R. W. (1996). The concept of carrying capacity for tourist destinations: Dead or merely buried? Progress in Tourism and Hospitality Research, 2(3), 283-292. https://doi.org/10.1002/pth.6070020309

Cánoves, G., Prat, J. M., \& Blanco, A. (2016). Turismo en España, más allá del sol y la playa. Evolución reciente y cambios en los destinos del litoral hacia un turismo cultural. Boletín de la Asociación de Geógrafos Españoles, 71, 431-454. https://doi.org/10.21138/bage.2289

Coastal Engineering Research Center, CERC (1984). Shore protection manual. Washington: United States Army Corps of Engineers.

Consejería de Turismo y Comercio (2015). Plan de Choque contra la estacionalidad del turismo andaluz (2014-2016). Sevilla: Junta de Andalucía. Retrieved from https://www.juntadeandalucia.es/export/drupaljda/pc_estacionalidad_litoralandaluz.pdf

Consejería de Turismo y Deporte (2017a). Balance del Año Turístico en Andalucía, 2017. Sevilla: Junta de Andalucía. Retrieved from

Consejería de Turismo y Deporte (2017b). Turismo litoral en Andalucía. Demanda turística en Andalucía. Segmentos turísticos, 2017. Sevilla: Junta de Andalucía. Retrieved from http://www.juntadeandalucia.es/turismoydeporte/opencms/estadisticas-consejeria/estadisticasturismo/index.html

Consejería de Turismo y Deporte (2017c). II Plan Choque contra la estacionalidad del turismo andaluz (2016-2018). Sevilla: Junta de Andalucía. Retrieved from https://www.juntadeandalucia.es/export/drupaljda/planes/16/10/II\%20Plan\%20Choque\%20 contra\%20la\%20Estacionalidad\%20Turistica\%20del\%20Litoral\%20Andaluz\%2016-18.pdf 
Crowell, M., Leatherman, S. P., \& Buckley, M. K. (1991). Historical shoreline change: error analysis and mapping accuracy. Journal of Coastal Research, 7(3), 839-852. Retrieved from https://www.jstor.org/stable/4297899?seq=1

Decreto-ley 12/2020, de 11 de mayo, por el que se establecen medidas urgentes y extraordinarias relativas a la seguridad en las playas, medidas administrativas en el ámbito educativo, y otras medidas complementarias ante la situación generada por el coronavirus (COVID-19). BOJA, 24, de 11 de mayo de 2020, pp. 11-51. Retrieved from https://www.juntadeandalucia.es/boja/2020/524/2

Decreto-ley 14/2020, por el que se establecen con carácter extraordinario y urgente medidas para la reactivación del sector de la hostelería, restauración, ocio y esparcimiento, se adoptan las medidas de apoyo a las Entidades Locales necesarias para contribuir a la apertura de playas seguras y otras medidas económicas y tributarias, ante la situación de alerta sanitaria generada por el coronavirus (COVID-19). BOJA, 30, de 27 de mayo de 2020, pp. 2-25. Retrieved from https://www.juntadeandalucia.es/boja/2020/530/1

Del Río, L., Benavente, J., Gracia F.J., Anfuso, G., Aranda, M., Montes, J.B., Puig, M., Talavera, L., \& Plomaritis, T.A. (2019): The Spanish Coastal Systems: dynamic processes, sediments and management. In J. A. Morales (Ed.), The Spanish Coastal Systems: Dynamic Processes, Sediments and Management (pp. 311-335). Cham: Springer.

Díaz, D. (2020, July 28). El vídeo de la playa de Chipiona que asombra al mundo: así es el sistema para controlar el Covid. El Español. Retrieved from https://www.elespanol.com/reportajes/20200728/video-playa-chipiona-asombra-sistemacontrolar-covid/508699656_0.html

Díaz-Cuevas, P., Prieto-Campos, A., \& Ojeda-Zújar, J. (2020a). Developing a beach erosion sensitivity indicator using relational spatial databases and Analytic Hierarchy Process. Ocean and Coastal Management, (189), 105146. https://doi.org/10.1016/j.ocecoaman.2020.105146

Díaz-Cuevas, P., Prieto-Campos, A., Fraile-Jurado, P., Ojeda-Zújar, J., Álvarez-Francoso, J.I. (2020b). Shoreline "Proxies" Evaluation for Mid-term Erosion Rates Calculation in Mesotidal and Microtidal Beaches (Andalusia, Spain). Journal of Coastal Research, (95, sp.1), 1062-1066. https://doi.org/10.2112/S195-207.1 
DPH (2005). Illinois Swimming Pool and Bathing Beach Code. Minimus Sanitary Requirements for Bathing Beaches. In Department of Public Health of Illinois State. Retrieved from http://www.ilga.gov/commission/jcar/admincode/077/07700820sections.html

Durán, C. (2020, June 5). Los 3.000 contratos para auxiliares de playa: ni saldrán de la bolsa única ni serán 1.900 euros netos. elDiario.es. Retrieved from https://www.eldiario.es/andalucia/contradicciones-transparencia-expectativas-frustradasauxiliares_1_6036731.html

Echamendi, P. (2001). La capacidad de carga turística. Aspectos conceptuales y normas de aplicación. Anales de Geografía de la Universidad Complutense, (21), 11-30. Retrieved from https://revistas.ucm.es/index.php/AGUC/article/view/AGUC0101110011A

Ekstein (2020, February, 13). The Coronavirus's Effect on Tourism Will Carry Into 2021. Experts Say. Bloomberg News. Retrieved from https://www.bloomberg.com/news/articles/2020-0213/coronavirus-s-effect-on-tourism-will-carry-into-2021-experts-say

Fernández, J.M. \& Bértola, G.R. (2014). Capacidad de carga turística de las playas del Partido de Mar Chiquita, Provincia de Buenos Aires, Argentina. Revista de Ciencias Minas y Costeras, (6), 55-73. http://dx.doi.org/10.15359/revmar.6.4

Fernandez-Nunez, M., Díaz, P., Ojeda, J., Prieto, A., \& Sanchez, N. (2015). Multipurpose line for mapping coastal information using a data model: the Andalusian coast (Spain). Journal of Coastal Conservation, (19), 461-474. https://doi.org/10.1007/s11852-015-0400-1

García, E. (2000). Los espacios turísticos en el litoral andaluz. Cuadernos Geográficos (30), 4376. Retrieved from: http://www.juntadeandalucia.es/educacion/vscripts/wbi/w/rec/1505.pdf Gómez, M. L. (2010). Los espacios naturales protegidos como categoría de ordenación del territorio en el caso de la comunidad autónoma andaluza. Cuadernos Geográficos, (47), $317-$ 346. Retrieved from http://www.ugr.es/ cuadgeo/docs/articulos/047/047-013.pdf

Hall, C.M., Scott, D., \& Gössling, S. (2020). Pandemics, transformations and tourism: be careful what you wish for. Tourism Geographies, 22(3), 577-598. https://doi.org/10.1080/14616688.2020.1759131

Hecock, R. D. (1983). Recreation behavior patterns as related to site characteristics of beaches. Journal Of Leisure Research †5, 37-250. https://doi.org/10.1080/00222216.1970.11970004 
Hunter, C. (1995). Key concepts for tourism and the environment. In Hunter, C. \& Green H. (eds.). Tourism and the Environment. A sustainable relationship? (pp. 52-92). London-New York: Routledge.

Instituto Geográfico Nacional, IGN (2018). Atlas nacional de España. Centro Nacional de Información Geográfica. Retrieved from http://atlasnacional.ign.es/wane/P\%C3\%A1gina_principal

Instituto Nacional de Estadística, INE (2020a). Encuesta de ocupación de campings. Retrieved from

https://www.ine.es/dyngs/INEbase/es/categoria.htm?c=Estadistica_P\&cid=1254735576863

Instituto Nacional de Estadística, INE (2020b). Encuesta de ocupación de apartamentos turísticos. Retrieved from

https://www.ine.es/dyngs/INEbase/es/categoria.htm?c=Estadistica_P\&cid=1254735576863 Instituto Nacional de Estadística, INE (2020c). Encuesta de Ocupación Hotelera. Retrieved from https://www.ine.es/dyngs/INEbase/es/categoria.htm?c=Estadistica_P\&cid=1254735576863 León, I. (2020, May 20). Ir duchado, no tragar agua y estar sólo cuatro horas: el decálogo para las playas andaluzas este verano. El Español. Retrieved from https://www.elespanol.com/espana/andalucia/20200519/ir-duchado-no-tragar-decalogoplayas-andaluzas/491201629_0.html

Ley 2/2013 de protección y uso sostenible del litoral y de modificación de la Ley 22/1988, de Costas, BOE, 129, de 30 de mayo de 2013, pp. 40691-40736. Retrieved from https://www.boe.es/diario_boe/txt.php?id=BOE-A-2013-5670

Lim, L. C. (1998). Carrying Capacity Assessment of Pulau Payar Marine Park, Malaysia - Bay of Bengal Programme. Retrieved from http://www.fao.org/tempref/Fl/CDrom/bobp/cd1/Bobp/Publns/Reports/0079.pdf

Martín-Serrano, A. (1985). La estructura de las unidades del Flysch del Campo de Gibraltar, consecuencias tectónicas y paleográficas. Boletín Geológico y Minero, 96(2), 3-26. Retrieved from http://doc.igme.es/BoletinGeoPDF/boletin\%2096\%20fasciculo\%202.pdf Ministerio para la Transición Ecológica y el Reto Demográfico, MITECO (AÑO). Guía de playas. Retrieved from https://www.miteco.gob.es/es/costas/servicios/guia-playas/default.aspx 
Moore, L.J.; Ruggiero, P., \& List, J. H. (2006). Comparing mean highwater and highwater line shorelines: Should proxy-datum offsets be incorporated into shoreline change analysis? Journal of Coastal Research, (224), 894-905. https://doi.org/10.2112/04-0401.1

Nieto, J.L., Román, I., Bonillo, D., \& Paulova, N. (2016). El turismo a nivel mundial. International Journal of Scientific Management and Tourism, 2(1), 129-144. Retrieved from https://dialnet.unirioja.es/servlet/articulo?codigo $=5665915$

NYS (2005). Bathing beach design standards. New York State. Retrieved from https://www.health.ny.gov/environmental/outdoors/swimming/

OECD (2018). OECD, Tourism, Trends and Policies. Paris: OECD Publishing. https://doi.org/10.1787/tour-2018-en

Ojeda, J. (1988). Particularidades morfodinámicas de la fachada ibérica del Golfo de Cádiz: geomorfología litoral. Revista de Estudios Andaluces, (10), 53-68. Retrieved from http://institucional.us.es/revistas/andaluces/10/art_4.pdf

Ojeda, J., Díaz, P., Prieto, A., \& Álvarez, J. I. (2013). Línea de costa y Sistemas de Información Geográfica: modelos de datos para la caracterización y cálculo de indicadores de la costa $\begin{array}{llll}\text { andaluza. } & \text { Investigaciones } & \text { 37-52. }\end{array}$ https://www.doi.org/10.14198/INGEO2013.60.02

Orden SND/440/2020, de 23 de mayo, por la que se modifican diversas órdenes para una mejor gestión de la crisis sanitaria ocasionada por el COVID-19 en aplicación del Plan para la transición hacia una nueva normalidad. BOE, 146, de 23 de mayo de 2020, pp. 34261-34272. Retrieved from https://www.boe.es/diario_boe/txt.php?id=BOE-A-2020-5265

Organización Mundial de la Salud, OMS (2019). Brote de enfermedad por coronavirus (COVID-19): orientaciones para el público. Retrieved from https://www.who.int/es/emergencies/diseases/novel-coronavirus-2019/advice-for-public

Organización Mundial del Turismo, OMT (1981). Saturation of Tourist Destinations, Report of the Secretary General. Madrid: Organización Mundial del Turismo. Retrieved from https://www.eunwto.org/doi/pdf/10.18111/unwtogad. 1981.1.un406362r557g40k

Organización Mundial del Turismo, OMT (2019). Panorama Internacional del Turismo. Madrid: Organización Mundial del Turismo. Retrieved from https://www.eunwto.org/doi/pdf/10.18111/9789284421237 
Organización Mundial del Turismo, OMT (2020). Impact assessment of the COVID-19 outbreak on international tourism. Retrieved from https://www.unwto.org/impact-assessment-of-the-covid19-outbreak-on-international-tourism

Organización Mundial del Turismo, OMT. (2005). Indicadores de desarrollo sostenible para los destinos turísticos: Guía práctica. Madrid: Organización Mundial del Turismo.

PDH (2002). A guide for the preparation of Applications, Reports, and Plans for Public Bathing Place Permits PART I| General Purpose Recreational Bathing Beaches Pennsylvania: Department of Health.

Pedrido, P., \& López, A. (2020, May 6). Sanxenxo dividirá la playa de Silgar en 780 cuadrículas con un aforo de hasta 2.340 personas. Faro De Viga. Retrieved from: https://www.farodevigo.es/portada-pontevedra/2020/05/06/sanxenxo-dividira-playa-silgar780/2284622.html

Peláez, A. (2020, April 30). Marcar cuadrículas en las playas: la iniciativa de Vélez-Málaga para poder bañarse este verano. DiarioSur. Retrieved from https://www. diariosur.es/axarquia/marcar-cuadriculas-playas-20200430170417-nt.html

Pereira da Silva, C. (2002). Beach Carrying Capacity Assessment: How important is it? Journal of Coastal Research, 36(sp1), 190-197. https://doi.org/10.2112/1551-5036-36.sp1.190

Prieto-Campos, A. (2017). Metodología para el cálculo, explotación y difusión de líneas de costa y tasas de erosión a medio plazo (1956-2011) en Andalucía (Doctoral dissertation, Universidad de Sevilla, Spain) (Unpublished). Retrieved from https://hdl.handle.net/11441/76160

Prieto-Campos, A., Díaz-Cuevas, P., Fernandez-Núnez, M., \& Ojeda-Zújar, J. (2018). Methodology for improving the analysis, interpretation, and geo-visualisation of Erosion Rates in coastal beaches-Andalusia, Southern Spain. Geosciences, (8), 335. https://doi.org/10.3390/geosciences8090335

Real Decreto 1071/2007, de 27 de julio, por el que se regula el sistema geodésico de referencia oficial en España. BOE n²07, de 29 de agosto de 2007, pp. 35986-35989. Retrieved from https://www.boe.es/eli/es/rd/2007/07/27/1071

Registro de Turismo de Andalucía (2020). Proyecto GNOIDE. Instituto de Estadística y Cartografía de Andalucía. Retrieved from http://gnoide.ideandalucia.es/ggiscloud/

Roig, F. X. (2002). Análisis de la Capacidad de Carga en los espacios litorales, calas y playas, situados en áreas naturales de especial interés de la Isla de Menorca. In P. Pumares, M. A. 
Asencio \& F. Fernández (Eds.), Turismo y transformaciones urbanas en el siglo XXI (pp. 325-335). Almería: Universidad de Almería.

Ruggiero, P., \& List, J.H. (2009). Improving Accuracy and Statistical Reliability of Shoreline Position and Change Rate Estimates. Journal of Coastal Research, (255), 1069-1081. https://doi.org/10.2112/08-1051.1

Santos, E. (2008). El desarrollo turístico del litoral de Huelva: factores, procesos y conflictos territoriales en un espacio turístico emergente (Doctoral dissertation, Universidad de Sevilla, Spain). Retrieved from

http://www.juntadeandalucia.es/turismocomercioydeporte/publicaciones/30799.pdf

Silva, S.F., \& Ferreira, J.C. (2013). Beach Carrying Capacity: The physical and social analysis at Costa de Caparica, Portugal. Journal of Coastal Research, (65), 1039-1044. https://doi.org/10.2112/SI65-176.1

Sistema de Información Multiterritorial de Andalucía, SIMA (2020). Banco de datos. Instituto de Estadística y Cartografía de Andalucía. Retrieved from https://www.juntadeandalucia.es/institutodeestadisticaycartografia/sima/index2.htm

Sridhar, E., Yuvaraj, V., Sachithanandam, T., Mageswaran, R., Purvaja, R. \& Ramesh, R. (2016). Tourism Carrying Capacity for Beaches of South Andaman Island, India. In Leszek (Ed.), Tourism - From Empirical Research Towards Practical Application (pp. 61-81). IntechOpen. https://doi.org/10.5772/62724

Villar, A. (2011). Territorio, turismo y paisaje: el proceso de urbanización en el litoral de Andalucía. El papel de los campos de golf. Sevilla: Consejería de Turismo, Comercio y Deporte. Vizcaíno, M. L. (2015). Evolución del turismo en España: El turismo cultural. International Journal of Scientific Management and Tourism, (4), 75-95. Retrieved from https://dialnet.unirioja.es/servlet/articulo?codigo=5665969

Yepes, V. (1999). Las playas en la gestión sostenible del litoral. Cuadernos de Turismo, (4), 89110. Retrieved from https://revistas.um.es/turismo/article/view/22881/22151

Yepes, V. (2020). Método simplificado de cálculo del aforo de las playas en tiempos de coronavirus. Universitat Politècnica de València. Retrieved from https://victoryepes.blogs.upv.es/2020/06/04/metodo-simplificado-de-calculo-del-aforo-de-lasplayas-en-tiempos-de-coronavirus/ 
Zhang, Z., Huang, W., Douglas, B., \& Leatherman, S. (2002). Shoreline position variability and long-term trend analysis. Shore and Beach, 70(2), 31-35. 
Anexo I. Superficie de playa excluida según causa y playas situadas a más de $2 \mathrm{~km}$ de distancia al último acceso

\begin{tabular}{|c|c|c|c|c|c|c|c|}
\hline Municipio & Construcción & Paseo & Militar & Sin acceso & $\begin{array}{l}\text { Superficie } \\
\text { excluida } \\
\text { (m2) }\end{array}$ & $\begin{array}{l}\text { Superficie } \\
\text { excluida } \\
\text { (\%) }\end{array}$ & Distancia $>2 \mathrm{Km}$ \\
\hline Almonte & 4704,54 & 48012,92 & 0,00 & 0,00 & 52717,45 & 15,4 & 1473642,76 \\
\hline Lepe & 46448,68 & 53528,82 & 0,00 & 0,00 & 99977,51 & 28,72 & 162762,06 \\
\hline Ayamonte & 1548,56 & 28248,55 & 0,00 & 0,00 & 29797,11 & 8,56 & 0,00 \\
\hline Punta Umbría & 4603,35 & 42059,42 & 0,00 & 0,00 & 46662,77 & 13,40 & 0,00 \\
\hline Palos de la Frontera & 0,00 & 55427,14 & 0,00 & 0,00 & 55427,14 & 15,92 & 0,00 \\
\hline Huelva & 0,00 & 17989,33 & 0,00 & 0,00 & 17989,33 & 5,16 & 71084,21 \\
\hline Isla Cristina & 1958,98 & 37352,57 & 0,00 & 0,00 & 39311,55 & 11,29 & 0,00 \\
\hline Cartaya & 448,46 & 5613,42 & 0,00 & 0,00 & 6061,88 & 1,74 & 0,00 \\
\hline Lucena del Puerto & 0,00 & 113,49 & 0,00 & 0,00 & 113,49 & 0,03 & 0,00 \\
\hline Moguer & 0,00 & 0,00 & 0,00 & 0,00 & 0,00 & 0,00 & 0,00 \\
\hline HUELVA & 59712,57 & 288345,67 & 0,00 & 0,00 & 348058,23 & 8,10 & 1707489,04 \\
\hline
\end{tabular}




\section{Anexo I. Continuación}

\begin{tabular}{|c|c|c|c|c|c|c|c|}
\hline Municipio & Construcción & Paseo & Militar & Sin acceso & $\begin{array}{l}\text { Superficie } \\
\text { excluida } \\
\text { (m2) }\end{array}$ & $\begin{array}{l}\text { Superficie } \\
\text { excluida } \\
\text { (\%) }\end{array}$ & Distancia $>2 \mathrm{Km}$ \\
\hline Tarifa & 745,32 & 95149,53 & 0,00 & 1664,67 & 95894,85 & 16,82 & 0,00 \\
\hline El Puerto de Santa María & 2329,14 & 40352,92 & 7029,00 & 0,00 & 49711,47 & 8,71 & 87101,12 \\
\hline Conil de la Frontera & 2423,76 & 40864,44 & 0,00 & 0,00 & 43288,20 & 7,58 & 0,00 \\
\hline Barbate & 635,97 & 73475,43 & 0,00 & 1000,01 & 74111,39 & 12,98 & 0,00 \\
\hline Cádiz & 3893,92 & 33597,85 & 29571,07 & 0,00 & 67062,84 & 11,75 & 0,00 \\
\hline Rota & 2325,55 & 49366,41 & 11662,84 & 0,00 & 63354,80 & 11,10 & 0,00 \\
\hline Sanlúcar de Barrameda & 5928,00 & 26303,39 & 0,00 & 0,00 & 32231,38 & 5,64 & 0,00 \\
\hline Chiclana de la Frontera & 4691,20 & 30190,49 & 0,00 & 0,00 & 34881,69 & 6,11 & 0,00 \\
\hline San Fernando & 915,85 & 14641,15 & 29642,83 & 0,00 & 45199,83 & 7,91 & 67314,26 \\
\hline Vejer de la Frontera & 907,22 & 19172,58 & 0,00 & 0,00 & 20079,80 & 3,51 & 0,00 \\
\hline Chipiona & 3299,69 & 37883,91 & 0,00 & 0,00 & 41183,61 & 7,21 & 0,00 \\
\hline Puerto Real & 0,00 & 3724,36 & 0,00 & 0,00 & 3724,36 & 0,65 & 0,00 \\
\hline CÁDIZ & 28095,62 & 464722,48 & 77905,74 & 2664,68 & 570724 & 11,23 & 154415,38 \\
\hline TOTAL & 87808,19 & 753068,15 & 77905,74 & 2664,68 & 918782,23 & 9,80 & 1861904,42 \\
\hline
\end{tabular}

Fuente: elaboración propia 
Anexo II. Usuarios potenciales

\begin{tabular}{|c|c|c|c|c|c|c|c|}
\hline Municipio & Población & Hoteles/Pensiones & Apartamentos & Campings & $\begin{array}{c}\text { Alojamientos } \\
\text { rurales }\end{array}$ & VFT* urbano & VFT rural \\
potenciales
\end{tabular}

Nota: ${ }^{*} \mathrm{VFT}=$ Viviendas con fines turísticos 


\section{Anexo II. Continuación}

\begin{tabular}{|c|c|c|c|c|c|c|c|c|}
\hline Municipio & Población & Hoteles/Pensiones & Apartamentos & Campings & $\begin{array}{c}\text { Alojamientos } \\
\text { rurales }\end{array}$ & VFT urbano & VFT rural & $\begin{array}{l}\text { Usuarios } \\
\text { potenciales }\end{array}$ \\
\hline $\begin{array}{l}\text { Sanlúcar de } \\
\text { Barrameda }\end{array}$ & 68684 & 788 & 34 & 0 & 0 & 2.545 & 48 & 72099 \\
\hline Chipiona & 19123 & 2749 & 418 & 0 & 0 & 1116 & 20 & 23426 \\
\hline Rota & 29109 & 3008 & 385 & 465 & 0 & 2619 & 0 & 35586 \\
\hline $\begin{array}{l}\text { El Puerto de } \\
\text { Santa María }\end{array}$ & 88405 & 2726 & 254 & 2715 & 112 & 4953 & 68 & 99233 \\
\hline Puerto Real & 41627 & 389 & 0 & 0 & 0 & 286 & 56 & 42358 \\
\hline Cádiz & 116027 & 2657 & 573 & 0 & 0 & 7571 & 0 & 126828 \\
\hline $\begin{array}{c}\text { San } \\
\text { Fernando }\end{array}$ & 94979 & 463 & 1178 & 0 & 0 & 309 & 0 & 96929 \\
\hline $\begin{array}{l}\text { Chiclana de } \\
\text { la Frontera }\end{array}$ & 84489 & 11254 & 426 & 659 & 0 & 7036 & 2731 & 106595 \\
\hline $\begin{array}{c}\text { Conil de la } \\
\text { Frontera }\end{array}$ & 22529 & 5177 & 508 & 7074 & 418 & 9144 & 4127 & 48977 \\
\hline $\begin{array}{c}\text { Vejer de la } \\
\text { Frontera }\end{array}$ & 12624 & 297 & 34 & 574 & 410 & 390 & 2633 & 16962 \\
\hline Barbate & 22518 & 1519 & 1351 & 2949 & 230 & 2041 & 437 & 31045 \\
\hline Tarifa & 18162 & 3686 & 810 & 4996 & 270 & 9288 & 766 & 37978 \\
\hline CÁDIZ & 618276 & 34713 & 5971 & 19432 & 1440 & 47298 & 10886 & 738016 \\
\hline TOTAL & 927735 & 57267 & 11190 & 35717 & 3871 & 56447 & 11278 & 1103505 \\
\hline
\end{tabular}

Fuente: Datos obtenidos del Sistema de Información Multiterritorial de Andalucía (2019) y del Registro de Turismo de Andalucía (2020) 